Fenno J. Christopher (Orcid ID: 0000-0002-7073-7855)

\title{
Treponema denticola increases MMP-2 expression and activation in the periodontium via reversible DNA and histone modifications
}

Islam M. Ateia ${ }^{1,5}$, Pimchanok Sutthiboonyapan ${ }^{1,6}$, Pachiyappan Kamarajan ${ }^{1,4}$, Taocong Jin ${ }^{2}$, Valentina Godovikova ${ }^{3}$, Yvonne L. Kapila ${ }^{1,4^{*}}$ and J. Christopher Fenno ${ }^{3 *}$

Running title: Epigenetic regulation of MMP-2 by T. denticola

Department of Periodontics and Oral Medicine ${ }^{1}$, Office of Research ${ }^{2}$, and Department of Biologic and Materials Sciences ${ }^{3}$, University of Michigan School of Dentistry, Ann Arbor, MI; Department of Orofacial Sciences, University of California San Francisco School of Dentistry, San Francisco, $\mathrm{CA}^{4}$; Department of Periodontics and Oral Medicine, University of Mansoura Faculty of Dentistry, Mansoura, Egypt ${ }^{5}$; Department of Periodontology, Chulalongkorn 3 University Faculty of Dentistry, Bangkok, Thailand ${ }^{6}$

* For correspondence. Email: fenno@umich.edu Phone: Phone: (+1) 734 763-3331 Fax: (+1) $734763-3453$

This is the author manuscript accepted for publication and has undergone full peer review but has not been through the copyediting, typesetting, pagination and proofreading process, which may lead to differences between this version and the Version of Record. Please cite this article as doi: $10.1111 / \mathrm{cmi} .12815$

This article is protected by copyright. All rights reserved. 


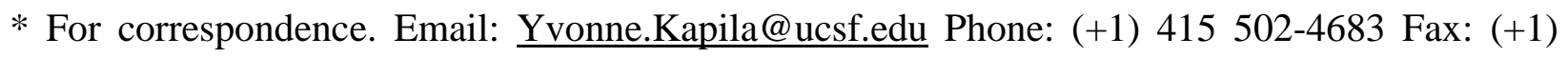
$415476-4204$

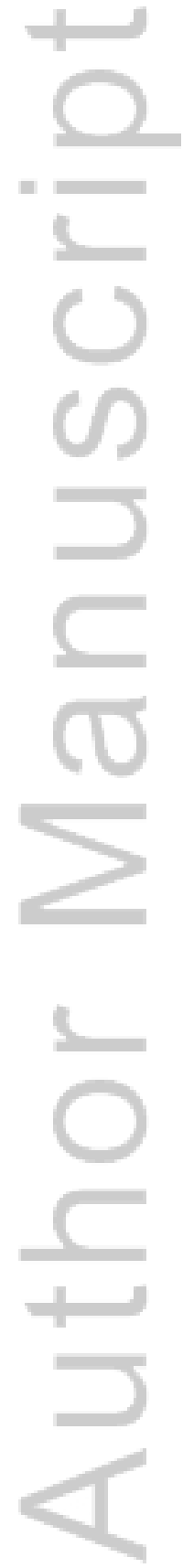

This article is protected by copyright. All rights reserved. 


\begin{abstract}
Host-derived matrix metalloproteinases (MMPs) and bacterial proteases mediate destruction of extracellular matrices and supporting alveolar bone in periodontitis. The Treponema denticola dentilisin protease induces MMP-2 expression and activation in periodontal ligament (PDL) cells, and dentilisin-mediated activation of pro-MMP-2 is required for cellular fibronectin degradation. Here we report that $T$. denticola regulates MMP-2 expression through epigenetic modifications in the periodontium. PDL cells were treated with epigenetic enzyme inhibitors before or after T. denticola challenge. Fibronectin fragmentation, MMP-2 expression and activation were assessed by immunoblot, zymography and qRT-PCR, respectively. Chromatin modification enzyme expression in T. denticola-challenged PDL cells and periodontal tissues were evaluated using gene arrays. Several classes of epigenetic enzymes showed significant alterations in transcription in diseased tissue and T. denticola-challenged PDL cells. $T$. denticolamediated MMP-2 expression and activation were significantly reduced in PDL cells treated with inhibitors of aurora kinases and histone deacetylases. In contrast, DNA methyltransferase inhibitors had little effect, and inhibitors of histone acetyltransferases, methyltransferases and demethylases exacerbated T. denticola-mediated MMP-2 expression and activation. Chronic epigenetic changes in periodontal tissues mediated by $T$. denticola or other oral microbes may contribute to the limited success of conventional treatment of chronic periodontitis and may be amenable to therapeutic reversal.
\end{abstract}




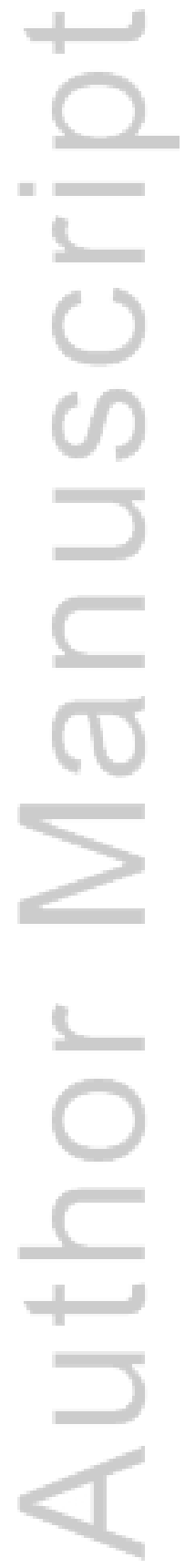

This article is protected by copyright. All rights reserved. 


\section{Introduction}

Periodontitis, a bacterially-mediated chronic inflammatory disease of the tissues supporting the tooth is one of the most common inflammatory diseases in humans and it can adversely affect systemic health (Armitage, 2004, Armitage, 2008). National surveys show that the majority of adults suffer from mild-to-moderate periodontitis, with up to $15 \%$ of the population being affected by severe forms at some stage in their lives (Pihlstrom et al., 2005). Periodontitis causes largely irreversible destruction of the periodontal tissues, and in advanced stages, tooth loss, speech and masticatory problems, and an overall reduced quality of life. Moreover, the systemic burden of periodontitis on different organs has been investigated. It has been reported that periodontal infections can adversely predispose to coronary heart diseases (Stewart et al., 2016), ischemic strokes (Leira et al., 2016), poor glycemic control (Garcia et al., 2015), preterm labor, low-birth-weight delivery (Sitholimela et al., 2013), and pulmonary diseases (Prasanna, 2011). These systemic effects have been attributed to either direct bacterial invasion or modulation of specific host inflammatory and tissue destructive mediators (Williams et al., 2008).

Destruction of the periodontal extracellular matrices (ECM) and detrimental changes in the cellular elements of the periodontal ligament occur as a result of disruption of normal tissue homeostatic processes. One of these disrupted processes is regulation of host-derived matrix metalloproteinases (MMP) that are both directly and indirectly involved in periodontal tissue breakdown. Destruction of the ECM in periodontitis results in the release of fibronectin (FN) fragments, which are considered markers of periodontal disease status (Huynh et al., 2002). 
Evidence from in vitro studies further indicate that these $\mathrm{FN}$ fragments, induce several detrimental effects, including induction of apoptosis and suppression of osteoblast differentiation of periodontal ligament cells (Kapila et al., 1996, Kapila et al., 1998, Kapila et al., 1999, Jee et al., 2004, Dai et al., 2005, Ghosh et al., 2008, Joseph et al., 2010), thereby further potentiating disease progression.

MMPs are synthesized in latent form, then activated through proteolytic cleavage to expose the catalytic site of the MMP enzyme. MMP activation is primarily extracellular, though intracellular activation is reported in certain cases (Nagase, 1997, Murphy et al., 1999). MMPs are synthesized at low basal levels for maintenance of homeostatic processes; however their levels and activation are typically increased during disease (Mittal et al., 2016). In addition to their role in remodeling the ECM and basement membrane during various physiologic processes, MMPs are implicated in a wide range of pathologic processes, including cardiovascular (Azevedo et al., 2014), pulmonary (Navratilova et al., 2016, Pardo et al., 2016), renal (Aresu et al., 2011, Charitaki et al., 2016), and gastrointestinal diseases (Medina et al., 2004), cancer (Endres et al., 2016, Ligi et al., 2016, Liu et al., 2016, Lukaszewicz-Zajac et al., 2016, Pietruszewska et al., 2016) and inflammatory diseases, such as periodontitis (Shinkarenko et al., 2013, Nissinen et al., 2014).

MMP-2, one of several MMPs involved in tissue homeostasis and remodeling, is constitutively expressed by periodontal ligament cells as pro-MMP-2 (Kapila et al., 1996). Thus, control of the process or rate of activation of MMP- 2 has been proposed as a key regulatory step 
in periodontal tissue homeostasis (Madsen et al., 2013, Mosig et al., 2013, Borkham-Kamphorst et al., 2015). Activation of pro-MMP-2 is promoted by proteolytic cleavage by the membrane type-1-MMP (MT1-MMP/MMP-14) (Nagase, 1997, Murphy et al., 1999, Zucker et al., 2003). Extracellular MMP activities are controlled by the blockage of autolytic MMP activation or by endogenous proteinase inhibitors, such as tissue inhibitors of MMPs (TIMPs) (Nagase et al., 2006, Brew et al., 2010). Regulation of the proteolytic activity of MMP-2 is dependent on the balance between MT1-MMP/TIMP-2 (Shofuda et al., 1998, Hernandez-Barrantes et al., 2001, Oyarzun et al., 2010). This mechanism of MMP-2 activation by an MT1-MMP-TIMP-2 complex has been well recognized in other systems (Strongin et al., 1995, Butler et al., 1998, Kinoshita et al., 1998). Disturbances in that balance may result in excessive tissue degradation associated with inflammatory diseases (Ejeil et al., 2003).

T. denticola along with Porphyromonas gingivalis and Tannerella forsythia become prevalent in late stages of subgingival biofilm formation and comprise the bacterial "red complex" that is considered pathogenic in the etiology of periodontal disease (Socransky et al., 1998). While our understanding of the periodontal disease microbiome has greatly increased, the "red complex" bacteria continue to be recognized as important pathogens in the disease process. Oral spirochetes including $T$. denticola often predominate in periodontal disease, though they are typically below detectable levels in healthy gingival plaque (Choi et al., 1994, Ellen et al., 2005). The levels of $T$. denticola increase with the severity of periodontitis, underscoring its major role in the disease (Simonson et al., 1988, Yoshida et al., 2004). 
Recognized virulence factors of $T$. denticola include the acylated serine protease complex (dentilisin; PrtP complex; CTLP/chymotrypsin-like protease) that degrades gelatin, laminin and various serum components and bioactive peptides (Uitto et al., 1988, Grenier et al., 1990, Makinen et al., 1995). The dentilisin complex contributes to $T$. denticola adherence and cytotoxic effects on epithelial cells and fibroblasts (Ellen et al., 1994, Mathers et al., 1996, Fenno et al., 1998), penetration of epithelial tissue (Chi et al., 2003), and it may play a role in complement-mediated bactericidal activity (McDowell et al., 2009) and complement evasion (McDowell et al., 2011). Of particular relevance to the current study, we previously demonstrated that dentilisin proteolytic activity induces activation of pro-MMP-2 in cultured PDL cells, and that activated MMP-2 is required for cleavage of cellular FN into fragments similar to those observed in gingival crevicular fluid from periodontal lesions (Miao et al., 2011). Furthermore, transcription and expression of MT1/MMP and TIMP-2 increased in response to $T$. denticola challenge (Miao et al., 2014). Taken together, these properties suggest important links between the $T$. denticola protease activity and regulation of the cellular and tissue processes that result in periodontal tissue destruction.

Epigenetics is defined as heritable and potentially reversible changes in gene expression without alterations in the DNA sequence (Goldberg et al., 2007, Waddington, 2012). Such modifications are not only associated with diseases but are also essential for the incorporation and integration of endogenous and environmental signals in cells. Epigenetic status can be affected by environmental factors, such as, nutrients, toxins, infections, and hypoxia with 
subsequent up- or down-regulation of specific gene expression patterns (Barros et al., 2009, Safronova et al., 2010, Bayarsaihan, 2011, Yin et al., 2011). Emerging evidence suggests that epigenetic modifications play a major role in inflammatory diseases, including periodontal disease (Barros et al., 2014). Several factors that mediate periodontal disease pathogenesis, including bacteria and their byproducts, smoking, and diabetes, induce marked epigenetic changes in tissue components (Offenbacher et al., 2008, Khansari et al., 2009, Medzhitov et al., 2009, Yin et al., 2011, Razzouk et al., 2013, Martinez et al., 2014, Pasquier et al., 2015). For example, chronically inflamed periodontal tissues demonstrated an increased methylation of CpG-rich regions of the PTGS2/COX2 promoter compared to healthy periodontal tissues (Zhang et al., 2010). Also, there is marked hypomethylation of the IL8 promoter in oral epithelial cells of subjects with Generalized Aggressive Periodontitis compared to control subjects (Andia et al., 2010). Emerging studies suggest that microbial pathogens, including oral species such as Porphyromonas gingivalis, induce epigenetic modifications in host cells (reviewed in (Niller et al., 2017)). We recently identified potential epigenetic links between $T$. denticola and genes in PDL cells involved in activation of MMP-2 (Miao et al., 2014). Thus, T. denticola may mediate epigenetic modifications that regulate MMP-2 activation and subsequent ECM degradation in the periodontium.

Epigenetic modifications are potentially reversible, and, therefore, a thorough understanding of these changes may identify new therapeutic targets for disease management. The aim of this study was to investigate $T$. denticola's ability to chronically activate MMP expression through 
epigenetic modifications in periodontal ligament cells/tissues, and to examine potential therapeutic approaches for reversal/modification of these changes.

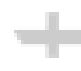

.

\section{Results}

\section{T. denticola chronically upregulates expression of MMP-2, MT1-MMP and TIMP-2,} with concomitant fibronectin fragmentation. To determine the long-term effects of a brief exposure to T. denticola on MMP-2 expression in host cells, PDL cells were briefly challenged with T. denticola, then MMP-2 expression and MMP-2 activation in long-term cultures with daily medium changes were assessed by gelatin zymography and qRT-PCR. As shown in Fig. 1A, PDL cells constitutively expressed basal levels of pro-MMP-2 with minimal activation for maintenance of homeostatic functions. However, challenge with $T$. denticola triggered both chronic increased MMP-2 expression (pro-MMP2) and activation (active MMP-2) in PDL cells. Following a $2 \mathrm{~h}$ exposure to $T$. denticola, dentilisin activity (visible as a $\sim 100 \mathrm{kDa}$ band on the zymogram, Fig. 1A) persisted within these cultures throughout the experiment, though it was detected at greatly reduced levels at days 9 and 12. Expression and activation levels of MMP-2 were chronically sustained for up to 12 days, with minor reductions in the levels of activated MMP-2 on days 9 and 12 (Fig. 1A). T. denticola-mediated increases in MMP-2 expression and activation were mirrored by concomitant fibronectin fragmentation throughout the experiment (Fig. 1B). 
The chronic effects of $T$. denticola on MMP-2 expression in PDL cells were regulated at the transcriptional level. MMP-2 mRNA levels were upregulated for up to 12 days as assessed by qRT-PCR (Fig. 1C). Given that the MT1-MMP/TIMP-2 complex is a well-known regulator of MMP-2 activation, MT1-MMP and TIMP-2 expression were examined in $T$. denticola challenged periodontal ligament cells in long-term cultures. Expression of the MT1MMP/TIMP-2 complex was also chronically upregulated by the $T$. denticola challenge, mirroring the changes induced in MMP-2 transcriptional expression (Fig. 1C).

\section{T. denticola levels and MMP-2 transcription are elevated in periodontal disease.} Examination of human tissues from periodontally diseased and healthy sites confirmed the association between $T$. denticola and elevated MMP-2 expression in diseased tissues. Human tissue specimens from periodontally diseased sites exhibited elevated levels of $T$. denticola concomitant with elevated levels of MMP-2 mRNA expression compared with healthy sites (Fig.

2). Tissue specimens from healthy sites exhibited negligible levels of $T$. denticola and low levels of MMP-2 expression. Low levels of MMP-2 expression in healthy tissues are consistent with the low basal levels of MMP-2 expression necessary for homeostatic functions within the periodontium, while increased MMP-2 expression is consistent with dysbiotic alterations of periodontal homeostasis in disease.

Expression of genes encoding chromatin modification enzymes are significantly altered in periodontal disease. To further examine the role of epigenetics in periodontal disease, the major chromatin modification enzymes that might be involved in the disease process (Table S1) 
were assessed via a focused gene array. Applying a "2-fold change" as a threshold value, we found that several chromatin modification enzymes were significantly altered in diseased periodontal tissue specimens compared to healthy control tissues (Fig. 3A, B and Table S2). The most significantly altered enzymes were the histone methyltransferases (HMTs) and histone deacetylases (HDACs), including PRMT8 and HDAC11, which exhibited a significant downregulation. Other enzymes, especially those related to SET Domain proteins, histone acetyltransferases (HATs), and histone phosphorylation kinases showed significant upregulation, such as SETD4, ESCO1, ESCO2, and AURKB. Other significantly altered enzymes included HATs, HDACs, histone ubiquitinases, DNA demethylases (DDMs) and histone demethylases (HDMs), and DNA methyltransferases (DNMTs).

\section{T. denticola significantly alters expression of genes encoding chromatin modification} enzymes in PDL cells. To examine the potential role of epigenetics in the $T$. denticola-mediated upregulation of MMP-2 expression, a focused gene array was employed to study all major epigenetic chromatin modification enzymes that might be involved in this process (Table S1). Applying a "2-fold change" as a threshold value, we found that $T$. denticola-challenged PDL cells exhibited significantly decreased levels of all major chromatin modification enzymes (and Fig. 3C, D and Table S3). No chromatin modifying enzymes assayed showed increased expression (data not shown). The most significantly down-regulated enzymes included aurora kinases, which mediate histone phosphorylation, and HMTs. Specifically, within these classes of enzymes, the most downregulated enzymes included Aurora Kinase B and EHMT2. Other 
significantly downregulated enzymes included HATs, histone deacetylases (HDAC), histone ubiquitinases, DNA (DDM) and histone demethylases (HDM), and DNMTs.

Inhibitors of histone kinase/aurora kinase, DNMT and HDAC block T. denticolamediated increases in MMP-2 activity and expression in PDL cells. Given the broad landscape of epigenetic changes mediated by $T$. denticola on PDL cells and the changes exhibited in diseased tissues, targeted approaches were employed to examine the role of representative members of each major class of epigenetic enzymes (Table 1) in the process of MMP-2 modulation and FN fragmentation in T. denticola-challenged PDL cells.

Pretreatment of PDL cells with the histone kinase/phosphorylation inhibitor, PF-03814735, inhibited the potential increase in MMP-2 activation and expression mediated by $T$. denticola (Fig. 4 A to C). Pretreatment with PF-03814735 also prevented the transcriptional increase in the MMP-2 activator complex, MT1-MMP /TIMP-2, and FN fragmentation mediated by the $T$. denticola challenge. This aurora kinase inhibitor exhibited a dose-response effect in terms of preventing the changes in MMP-2 expression and activation. At the highest dose tested, PF03814735 also suppressed MMP-2 expression and activation in control cells. All enzyme inhibitor concentrations were selected in ranges that did not alter proliferation or induce cytotoxicity in PDL cells (data not shown).

Prevention of the potential increase in MMP-2 activation and expression mediated by $T$. denticola was also achieved by pretreatment of PDL cells with Azacytidine (AZA), a DNMT inhibitor (Fig. 5 A to C). AZA had a dose-response effect, inhibiting increases in MMP-2 
expression and activation, MT1-MMP/TIMP-2 expression, and fibronectin fragmentation mediated by the T. denticola challenge. In contrast, epigallocatechin gallate (EGCG), a different DNMT inhibitor with a broad spectrum of activity that includes inhibition of HATs, had considerably less effect than AZA. At the highest concentration tested, EGCG had only minor effects on T. denticola-mediated MMP-2 activation and TIMP-2 expression, but this did not result in modulation of FN fragmentation (Fig. 6 A to C).

Examination of HDAC inhibitors Apicidin and Trichostatin revealed that pretreatment with these two inhibitors at the highest doses tested $(1 \mu \mathrm{M}$ and $0.1 \mu \mathrm{M}$, respectively) also inhibited the $T$. denticola-mediated increase in MMP-2 expression and activation as well as that of its activator complex, MT1-MMP/TIMP-2. However, as with EGCG, neither of these inhibitors affected $\mathrm{FN}$ fragmentation (data not shown).

\section{HMT, HDM and HAT inhibitors exacerbate $T$. denticola-mediated increases in MMP-2} expression and activity in PDL cells. Inhibitors of histone demethylases (HDM), histone methyltransferases (HMT), and histone acetyltransferases (HAT) were not effective in preventing the $T$. denticola-mediated increases in pro-MMP-2 expression and activation. Treatment with Curcumin, a HAT inhibitor, resulted in moderately increased expression of proMMP-2, but significantly decreased its MMP-2 activation in a dose-dependent manner (Fig. 7A). In contrast, the HDM inhibitor, Tranylcypromine, $\mathrm{HCl}$ (TCP) and the HMT inhibitor, BIX 01295/ trihydrochloride hydrate further augmented the T. denticola-mediated increases in MMP2 expression and activation in PDL cells (Fig. 7B, C). 


\section{Inhibitors of histone phosphorylation and histone deacetylase reverse $T$. denticola-}

mediated increases in MMP-2 activity and expression in PDL cells. An important remaining question was whether existing epigenetic modifications on periodontal ligament cells mediated by $T$. denticola could be reversed in a post-treatment scenario. To this end, periodontal ligament cells were first challenged with $T$. denticola then the same enzyme inhibitors tested above were employed to address this question. In agreement with the pretreatment results, post-treatment of T. denticola challenged PDL cells with three different epigenetic enzyme inhibitors reversed the effects on MMP-2 expression and activation: the histone kinase inhibitor, PF-03814735 (Fig. 8A) and the HDAC inhibitors apicidin (Fig. 8B) and trichostatin (Fig. 8C).

It is important to note that the results of the pre- and post-challenge inhibition experiments should not be compared in parallel because of different sample collection times used. In the pretreatment experiments, samples were collected after 3 days of a T. denticola (2-hour exposure) challenge, whereas in the post-challenge treatment experiments, the samples were collected 2 hours to 4 days after a $T$. denticola (2 hour exposure) challenge, depending on the inhibitor used. Similarly, in contrast to the pre-challenge enzyme inhibition experiments, no decrease in FN fragmentation was observed in post-challenge inhibition experiments (data not shown), presumably because the MMP-2-mediated fragmentation process had begun before addition of enzyme inhibitors.

\section{Discussion}


ECM destruction, a key event in the pathogenesis of periodontitis, is mediated by host-derived enzymes such as MMP-2 that are involved in ECM homeostasis and remodeling. Strong evidence has accumulated over the past two decades that bacterial components, including proteases and lipopolysaccharides, are key factors contributing to dysregulation of ECM homeostasis. It is of particular interest that activation of pro-MMP-2, which is constitutively expressed in PDL cells, is required for the fragmentation of cellular FN that is typically seen in periodontal disease (Miao et al., 2011). Thus, identifying factors that control MMP-2 expression or activation can help us better understand and modulate periodontal disease pathogenesis.

T. denticola is a member of a very complex microbiota involved in the pathogenesis of periodontal diseases. MMP-2 production and activation is a major event in the pathogenesis of these diseases via its role in extracellular matrix destruction. The $T$. denticola dentilisin protease plays an important role in the up-regulation and activation of MMP-2 in PDL cells (Miao et al., 2011, Miao et al., 2014), thereby promoting further ECM destruction and release of fibronectin fragments, which have deleterious effects on the periodontal environment (Kapila et al., 1996, Kapila et al., 1999, Kapila et al., 2002, Jee et al., 2004, Dai et al., 2005, Tafolla et al., 2005, Ghosh et al., 2008, Joo et al., 2008, Joseph et al., 2010, Miao et al., 2011, Miao et al., 2014, Pereira et al., 2014). The oral spirochete T. lecithinolyticum is also reported to activate MMP-2, as are $P$. gingivalis and A. actinomycetemcomitans (Choi et al., 2001, Chang et al., 2002, Song et al., 2003). The molecular mechanism(s) involved remain unstudied or unresolved for these species. 
T. denticola dentilisin activity was present for several days in PDL cell conditioned medium, long after the brief ( 2 hour) challenge, washing and multiple changes of growth medium. This is consistent with our prior reports (Miao et al., 2011, Miao et al., 2014) and is likely due to persistent adherence of $T$. denticola to PDL cells, though we cannot yet rule out potential downstream effects of previously documented uptake of $T$. denticola by PDL cells (Miao et al., 2014) and gingival epithelial cells (Shin et al., 2012, Jo et al., 2014, Inagaki et al., 2016). Importantly, while dentilisin activity levels decreased steadily over time, MMP-2 and its activating complex, MT1-MMP and TIMP-2, were clearly expressed and activated through the 12th day of culture. These data confirm our previous results that dentilisin is an important factor in the activation of pro-MMP-2 (Miao et al., 2011). Additionally, in agreement with our earlier findings (Miao et al., 2014), the current data show that $T$. denticola chronically activates MMP2, in concert with MT1-MMP and TIMP-2 expression up to 12 days. Importantly, degradation of cellular FN in PDL cell cultures is dependent on MMP-2 activation, which is the result of $T$. denticola dentilisin activity (Miao et al., 2011). The persistent fibronectin fragmentation in these samples may help explain the chronicity of tissue destruction mediated by bacterial proteases during periodontal disease pathogenesis.

Previous studies showed that $T$. denticola has the ability to adhere to and be internalized by several different host cells, including gingival epithelial cells, PDL cells, and polymorphonulear leukocytes (Ding et al., 1997, Konermann et al., 2012, Shin et al., 2012, Miao et al., 2014). It should be noted that, unlike other oral pathogens, such as Porphyromonas gingivalis which 
exhibits a cellular-invasive phenotype (Lamont et al., 1995), there is no reported evidence that $T$. denticola survives in the intracellular environment. Taken in aggregate, these results and the findings from this study, support the concept that the alteration of the PDL cells towards a destructive phenotype is a consequence of exposure to $T$. denticola. These data are consistent with evidence from other inflammatory diseases pointing toward an epigenetic role in the pathogenic process. We hypothesized that epigenetic mechanisms may imprint the periodontium and set in motion the process of chronic periodontal tissue destruction.

Mechanisms of epigenetic modifications include, histone acetylation, histone methylation, DNA methylation, positioning of histone variants, and gene regulation by non-coding micro RNAs (miRNAs) (Bayarsaihan, 2016, Herceg, 2016, Perkins et al., 2016). Several enzymes are involved in these mechanisms including; histone acetyltransferases (HATs), histone deacetylases (HDACs), histone methyltransferases (HMTs), histone demethylases (HDMs), histone phosphorylases, and DNA methyltransferases (DNMTs).

Perturbing the balance between acetylation/deacetylation or methylation/demethylation is profoundly associated with numerous diseases including developmental abnormalities, cancer and chronic inflammatory conditions (Bird, 2002, Barros et al., 2009). Epigenetic modifications are potentially reversible; therefore, a thorough understanding of these changes may identify new therapeutic targets for disease management. Using gene arrays that target chromatin modification enzymes, our data provides the first evidence that $T$. denticola mediates downregulation of many of these enzymes in PDL cells. In similar studies, P. gingivalis lipopolysaccharides were shown 
to downregulate many chromatin modification enzymes in cultured oral keratinocytes (de Camargo Pereira et al., 2013) and change the expression of multiple miRNAs in PDL cells (Du et al., 2016). However, since $T$. denticola-dependent MMP-2 activation requires dentilisin proteolytic activity (Miao et al., 2011), it is likely that the molecular mechanisms responsible for this downregulation differ from those driven by $P$. gingivalis lipopolysaccharides. Specific mechanisms by which $T$. denticola or its dentilisin protease may regulate epigenetic enzyme expression are under study in our laboratories.

The association between $T$. denticola and periodontitis has been reported in numerous studies (Simonson et al., 1988, Sakamoto et al., 2001, Asai et al., 2002, Yoshida et al., 2004). Consistent with the existing literature, we found that $T$. denticola levels were significantly elevated in human tissue specimens from periodontally diseased sites compared with healthy sites, as measured by qPCR normalized to human GAPDH (data not shown). To date, studies of the role of epigenetic modifications in periodontal disease have focused on DNA methylation patterns in genes involved in inflammatory responses (Barros et al., 2014). The present study used gene array approaches to examine healthy and diseased periodontal tissues, revealing for the first time significant alterations in the expression of several chromatin modification enzymes in diseased tissues. Although expression levels of some enzymes (such as Aurora Kinase B) differed in the gene array of the PDL cells compared to the tissues, this likely reflects the fact that tissues exhibit the net expression of diverse cell types that comprise the periodontium, as 
well as the net effects of the diverse oral microbiome on the periodontium, and net effects of other epigenetic effectors, including smoking and medications.

Different inhibitors show promise in reversing epigenetic changes in the context of our study and in other reports. Chronic T. denticola-mediated MMP-2 expression and activation were decreased in T. denticola challenged PDL cells either pre- or post-treated with inhibitors of histone phosphorylases, histone deacetylases (HDACs), and DNA methyltransferases (DNMTs). This indicates that $T$. denticola induces epigenetic changes mediated by histone phosphorylation, histone deacetylation, or DNA methylation pathways. Specifically, pre- or post-treatment inhibition of histone phosphorylation in PDL cells using PF-03814735 significantly prevented or reversed the $T$. denticola-mediated increase in MMP-2 and the MT1-MMP/TIMP-2 complex. This study is the first to show the effect of inhibition of histone phosphorylation on MMP-2 expression in PDL cells. In a broader context, PF has been used in phase I clinical trials for the treatment of advanced solid tumors (Jani et al., 2010, Schoffski et al., 2011).

Inhibition of HDACs using Apicidin and/or Trichostatin was also effective in preventing or reversing the T. denticola-mediated effects on the expression of MMP-2 in PDL cells. Similar data were obtained by other studies investigating the effect of Trichostatin on MMP-2 expression in murine fibroblasts (Ailenberg et al., 2002). Trichostatin was further shown to decrease MMP2 and MMP-9 expression in murine heart cells (Mani et al., 2015) and in human esophageal squamous cell carcinoma cells (Wang et al., 2013). Trichostatin, in combination with SAHA, was reported to inhibit the respiratory syncytial virus (RSV)-mediated increase in HDAC2 
expression with resultant decrease in airway inflammation and oxidative stress in vivo (Feng et al., 2016). Apicidin was also reported to inhibit the expression of MMP-2 in different cancer cells (Kim et al., 2000, Park et al., 2011, Ahn et al., 2012). On the other hand, inhibition of DNMTs using AZA showed a reduction in the expression of MMP-2 and its activating complex, while the use EGCG was not effective in this process.

Our results are consistent with those in other studies reporting that AZA causes a downregulation of MMP-2 and MMP-9 expression in cultured esophageal squamous cell carcinoma cells (Liu et al., 2014) and breast cancer cells (Chang et al., 2014b) respectively. AZA was approved by the U. S. Food and Drug Administration (FDA) for treatment of myelodysplastic syndromes (Nebbioso et al., 2012). It was also investigated in many clinical trials for treatment of several disorders, including hematological and neoplastic disorders (Liu et al., 2005, Mirza et al., 2010, Chen et al., 2012). Regarding the effect of EGCG on MMP-2 expression in our study, the data are inconsistent with other studies, which reported the ability of EGCG to inhibit MMP2 in different cancer cells (Chang et al., 2014a, Nowakowska et al., 2016). This inconsistency may be due to the use of different cell types, different concentrations of EGCG, or both. Concentrations higher than $10 \mu \mathrm{M}$ were toxic to PDL cells as examined by cell proliferation and cytotoxicity assays (data not shown). Due to the weak effect of EGCG on the expression of MMP-2, we did not test its effects in a post-challenge scenario.

Negative consequences of using epigenetic enzyme inhibitors are possible, as seen in the current study. Specifically, some inhibitors, namely those inhibiting HDM with TCP and those 
inhibiting HMT with BIX 01295, further increased MMP-2 expression and activation. Although TCP and BIX are thought to mediate opposite actions, namely BIX inhibits histone methylation and TCP promotes histone methylation, both increased MMP-2 expression and activation. Thus, due to these undesirable effects, BIX and TCP were not evaluated further in post-challenge scenarios. There are no previous studies investigating their effect on expression of MMPs. However, Pereira et al. showed that increases in MMP-2 expression were stimulated by decreases in histone methylation in the context of the MMP-2 promoter (Pereira et al., 2014). Additionally, in another study, the MMP-1, 3, 9, and 13 genes were shown to be actively transcribed in rheumatoid arthritis-derived synovial fibroblasts, and this transcription correlated with an elevation in $\mathrm{H} 3 \mathrm{~K} 4 \mathrm{me} 3$ and suppression of $\mathrm{H} 3 \mathrm{~K} 27 \mathrm{me} 3$ in the MMP promoter genes (Araki et al., 2016). These studies, which both showed increases in MMP-2 expression despite different degrees of histone methylation, can be explained by the fact that activation or repression of gene expression by histone modifications/methylations depends on the type of lysine being modified and the degree of its methylation. For example, H3K4me, H3K36me, or H3K79me are associated with transcriptional activation (Jenuwein et al., 2001, Zhang et al., 2001, Barski et al., 2007, Guenther et al., 2007, Koch et al., 2007, Kouzarides, 2007), whereas $\mathrm{H} 3 \mathrm{~K} 9 \mathrm{me}, \mathrm{H} 3 \mathrm{~K} 27 \mathrm{me}$, or H4K20me are implicated in gene repression (Jenuwein et al., 2001, Nakayama et al., 2001, Talbert et al., 2006, Barski et al., 2007, Kouzarides, 2007).

The HAT inhibitor curcumin also increased the expression of MMP-2 but significantly inhibited its activation. The effect of curcumin in decreasing MMP-2 and MMP-9 expression 
levels was reported in cancer cells, such as squamous cell carcinoma and osteoclastoma (Cao et al., 2015, Lee et al., 2015). Additionally, in vivo studies in humans and animals demonstrated curcumin's effectiveness in decreasing the severity of periodontal diseases (Elburki et al., 2014, Nagasri et al., 2015, Bakir et al., 2016, Elburki et al., 2016). Curcumin has been investigated in many clinical trials for treatment of several disorders, such as ulcerative colitis (Baliga et al., 2012), breast cancer (Nagaraju et al., 2012), pancreatic cancer (Veeraraghavan et al., 2011), and diabetes (Abdel Aziz et al., 2012). Additional investigation into the role of curcumin in MMP activation and regulation in periodontal diseases is further warranted, given these reports and the current study findings.

In summary, $T$. denticola plays a key role in the transcriptional regulation of MMP-2 and its activating complex MT1-MMP/TIMP-2 in PDL cells. T. denticola also mediates alterations of chromatin modification enzyme expresssion in PDL cells, and an array of epigenetic modifications are associated with periodontally diseased tissues. Furthermore, inhibition of enzymes that mediate epigenetic modifications can prevent $T$. denticola-mediated increases in MMP-2, MT1-MMP, and TIMP-2 in PDL cells. These inhibitors can also reverse the $T$. denticola-mediated effects on MMP-2 and its activating complex in PDL cells. These data indicate that $T$. denticola mediates its effects on MMP-2 activation through epigenetic modifications in these cells. This knowledge can be useful as a first step toward the development of novel targeted therapeutics for the treatment of periodontal diseases. 


\section{Materials and Methods}

Periodontal ligament (PDL) cell culture. As described previously, the primary culture of PDL cells was obtained via the direct cell outgrowth method by isolating cells from the PDL tissue around the middle third of extracted healthy human teeth (Scanlon et al., 2011, Tanaka et al., 2011). Cells were maintained in minimal essential medium- $\alpha$ (MEM- $\alpha$ ) augmented with $10 \%$ fetal bovine serum (FBS), 1\% penicillin/streptomycin (P/S), and 1\% amphotericin B (Gibco, Grand Island, NY, USA) in a humid atmosphere with $95 \%$ air and $5 \% \mathrm{CO}_{2}$ at $37^{\circ} \mathrm{C}$. Cell outgrowths were passaged when they reached confluency. Cells passaged three to six times were used for experimentation. The cell counting kit-8 (Dojindo, Rockville, MD, USA) was used for assaying PDL cell proliferation and cytotoxicity at different time intervals in response to different concentrations of the inhibitors used in the study (data not shown). Protocols involving the collection and use of human teeth and PDL cells/tissue were approved by the Health Sciences Institutional Review Board of the University of Michigan.

Human periodontal tissues. Periodontal tissues were obtained by collecting the tissues around the coronal third of the roots of extracted periodontally-involved teeth and healthy teeth, both from the posterior mandibular region. Periodontal status was diagnosed clinically by testing for bleeding on probing of the gingival sulcus and periodontal pocket depth measurements. The samples were collected from six different periodontitis patients and six healthy subjects. The collection and use of human teeth and PDL tissues was approved by the Health Sciences Institutional Review Board of the University of Michigan. 
Culture of Treponema denticola. Treponema denticola ATCC 35405 was grown as described previously under anaerobic conditions at $37^{\circ} \mathrm{C}$ in New Oral Spirochete (NOS) broth medium (Haapasalo et al., 1991, Fenno, 2005). Purity of spirochete cultures was confirmed by darkfield microscopy prior to use in experiments.

Challenge of PDL cells with Treponema denticola. PDL cells were prepared in MEM- $\alpha$ free of serum and antibiotics. The bacteria in broth culture were collected by centrifugation, then resuspended in serum- and antibiotic-free MEM- $\alpha$ to an optical density of 0.1 at $600 \mathrm{~nm}$, such that the cellular density was approximately $2.4 \times 10^{8}$ cells $/ \mathrm{ml}$.

T. denticola in serum-and antibiotic-free MEM- $\alpha$ was added to the test group of PDL cells (T. denticola group) at a multiplicity of infection $(\mathrm{MOI})=100$, whereas only MEM- $\alpha$ was added to the control group. Both groups were then incubated for two hours at $37^{\circ} \mathrm{C}$ in $5 \% \mathrm{CO} 2$ containing air. After the two-hour challenge, PDL cells were washed three times with PBS and incubated for the planned time periods in serum-and antibiotic-free MEM- $\alpha$ with daily medium changes as described previously (Miao et al., 2011). Subsequently, the culture conditioned medium and cell lysates were collected, RNA was extracted from the cell lysates, and all samples were stored at $-80^{\circ} \mathrm{C}$ for further investigations.

Pre-challenge inhibition of epigenetic chromatin modification enzymes in PDL cells, Different inhibitors of epigenetic chromatin modification enzymes (listed in Table 1) were obtained and prepared according to the manufacturer's instructions, then brought to the desired concentrations via dilution in serum- and antibiotic-free MEM- $\alpha$. With the exception of 
tranylcypromine (EMD Millipore, Temecula, CA, USA), all enzyme inhibitors were purchased from Sigma Aldrich (St. Louis, MO, USA).

PDL cells were treated with the indicated concentrations of the enzyme inhibitors either as single agents or in combinations, and incubated for the indicated times with daily culture medium replacement. The cells were then challenged with T. denticola at an MOI of 1:100 for 2 hours, washed, and incubated for three days in serum- and antibiotic-free MEM- $\alpha$ with daily culture medium refreshment. At the end of this incubation period, conditioned culture medium and cell lysates were harvested and stored at $-80^{\circ} \mathrm{C}$ for further investigations.

Post-challenge inhibition of epigenetic chromatin modification enzymes in PDL cells. For the post-challenge experiments, the PDL cells were first challenged with $T$. denticola as described before, then treated with the indicated concentrations of the inhibitors either as single agents or in combinations for certain periods. At the end of the treatment period, the conditioned culture medium and cell lysates were harvested and stored at $-80^{\circ} \mathrm{C}$ for further investigations. All experiments were repeated at least three times and each experiment was performed in triplicate.

Gelatin zymography. Culture supernatants were concentrated approximately 10 -fold in Amicon centrifugal concentrators (10,000-molecular-weight cutoff; Millipore) and total protein concentration was measured using the BCA protein assay kit (Thermo Scientific, Rockford, IL, USA) normalized to an albumin standard. Equivalent protein concentrations from each sample were mixed with non-reducing sample buffer $(0.25 \mathrm{M}$ tris-base, $40 \%$ glycerol, $0.8 \%$ SDS, and $0.05 \%$ bromophenol blue stain in distilled deionized water/ $\mathrm{ddH}_{2} \mathrm{O}$ at $\mathrm{pH} 6.8$ ) and loaded into $8 \%$ 
polyacrylamide gels co-polymerized with $0.4 \%$ SDS and $0.2 \%$ gelatin. Samples were electrophoretically resolved on gelatin-containing gels at $125 \mathrm{~V}$ for 110 minutes at $4^{\circ} \mathrm{C}$. Gels were then washed twice for 15 minutes under continuous agitation using renaturation/washing buffer $\left(2.5 \% \mathrm{v} / \mathrm{v}\right.$ Triton-X100 and $0.05 \mathrm{M}$ Tris-base in $\mathrm{ddH}_{2} \mathrm{O}$ at $\left.\mathrm{pH} 7.5\right)$ to eliminate SDS and promote the renaturation of MMP enzymes. Subsequently, gels were incubated in developing/incubation buffer $(0.05 \mathrm{M}$ Tris-base, $0.15 \mathrm{M}$ sodium chloride, $0.01 \mathrm{M}$ calcium chloride, and $0.02 \%$ sodium azide in $\mathrm{ddH}_{2} \mathrm{O}$ at $\mathrm{pH} 7.5$ ) for 30 minutes under agitation, then the buffer was replaced and gels incubated for $16-20$ hours at $37^{\circ} \mathrm{C}$. After that, gels were stained using filtered Coomassie Brilliant blue stain for one or two hours under agitation. Destaining of the gels was performed using a methanol/acetic acid destaining buffer (40\% methanol and 10\% acetic acid in $\mathrm{ddH}_{2} \mathrm{O}$ ) until the bands on the gel appeared clear. Zymograms were scanned and the densitometry of the gelatinolytic activity represented by the clear bands was analyzed using ImageJ software (NIH, USA). Brightness and contrast levels of zymogram images were slightly adjusted for publication only.

Immunoblotting. Equivalent protein samples consisting of 10 fold concentrates of PDL cell culture conditioned media were standardized as described above, subjected to standard SDSPAGE (4-12\% polyacrylamide gels; Invitrogen, Carlsbad, CA, USA) and transferred to PVDF membranes using standard techniques. The membranes were exposed to a rabbit polyclonal antifibronectin IgG (Santa Cruz, Dallas, TX, USA) primary antibody diluted 1:2000 in TBST solution for 2 hours at room temperature followed by a horseradish peroxidase (HRP)-conjugated 
goat anti-rabbit IgG secondary antibody (Santa Cruz, Dallas, TX, USA) diluted 1:10,000 in TBST for 1 hour at room temperature with agitation. Western blots using anti-GAPDH antibodies were used to further confirm equal protein loading (data not shown). Blots were developed using the SuperSignal ${ }^{\circledR}$ West Pico kit (ThermoFischer Scientific, Pittsburgh, PA, USA) and scanned for digitization.

Quantitative reverse transcriptase PCR (qRT-PCR). qRT-PCR was performed to assess the transcriptional levels of MMP-2, MT1-MMP, and TIMP-2 in PDL cells. Cell lysates were collected and the RNA was extracted and purified using the RNeasy ${ }^{\circledR}$ mini kit (Qiagen, Valencia, CA, USA) according to the manufacturer's instructions. Reverse transcription of the RNA into cDNA was then performed using the SuperScript ${ }^{\mathrm{TM}}$ II RT kit (Invitrogen, Carlsbad, CA, USA). The cDNA was then amplified by qPCR using the TaqMan $^{\circledR}$ Universal PCR Master Mix (Invitrogen, Carlsbad, CA, USA)" on a ViiA ${ }^{\mathrm{TM}} 7$ Applied Biosystems ${ }^{\circledR}$ PCR system. The following TaqMan ${ }^{\circledR}$ human probes were used; MMP-2 (Hs01548727_m1), MT1-MMP (Hs01037003_g1), TIMP-2 (Hs00234278_m1), and GAPDH (Hs03929097_g1) (Invitrogen, Carlsbad, CA, USA). The cycle threshold $\left(\mathrm{C}_{\mathrm{t}}\right)$ values were obtained, analyzed and the quantitative expression of target genes in challenged PDL cells was normalized to GAPDH and compared to the control cells using the $2^{-\Delta \Delta C T}$ method (Livak et al., 2001), applying a minimum 2 fold change in expression as the cut off.

Similar methodology was utilized to assess the levels of MMP-2 transcription and the levels of $T$. denticola in human periodontal tissue samples. Periodontal tissue specimens were collected 
by scraping the most coronal portion of the tissue around the roots of extracted healthy and periodontally-diseased teeth. Total RNA was extracted from healthy and diseased periodontal tissue specimens and cDNA was generated. Target genes were amplified using TaqMan ${ }^{\circledR}$ Universal PCR Master Mix (Invitrogen, Carlsbad, CA, USA). Tissue sample human genome content was normalized using a custom TaqMan $^{\circledR}$ primer/probe set for GAPDH (Hs03929097_g1; Invitrogen, Carlsbad, CA, USA). T. denticola 16S rRNA was amplified in parallel using the SYBR ${ }^{\circledR}$ Green PCR Master Mix (Invitrogen, Carlsbad, CA, USA) with the following primer set: 16SrRNA-987F AGGGATATGGCAGCGTAGCA and 16SrRNA-1077R TTGCGGGACTTAACCCAACA.

Quantitative reverse transcription (qRT-PCR) gene micro-array. qRT-PCR arrays were used to assess the transcriptional levels of the main epigenetic chromatin modification enzymes in cultured PDL cells and in periodontal tissues using the RT ${ }^{2}$ Profiler PCR Array kit (Qiagen, Valencia, CA, USA) to assay transcription of the genes listed in Table S1. Periodontal tissue specimens were collected by scrapping the most coronal portion of the tissue around the roots of extracted healthy and periodontally-diseased teeth. RNA was extracted and purified from PDL cell cultures using the RNeasy ${ }^{\circledR}$ Mini kit, while extraction and purification of RNA from periodontal tissues was achieved using the RNeasy ${ }^{\circledR}$ Protect Mini kit (Qiagen, Valencia, CA, USA) according to the manufacturer's protocol. Reverse transcription of RNA into cDNA was performed using the $\mathrm{RT}^{2}$ First Strand Kit (Qiagen, Valencia, CA, USA). The target genes were then amplified using the $\mathrm{RT}^{2}$ Profiler PCR Array kit and $\mathrm{RT}^{2} \mathrm{SYBR}^{\circledR}$ Green Master mix 
(Qiagen, Valencia, CA, USA) on a ViiA ${ }^{\mathrm{TM}} 7$ Applied Biosystems ${ }^{\circledR}$ PCR system. Applying a minimum 2 fold change in expression as the cut off, $\mathrm{C}_{\mathrm{t}}$ values were analyzed and the quantitative expression of the genes of interest in $T$. denticola-challenged PDL cells was normalized to supplied housekeeping genes; $\beta$-actin, Glyceraldehyde-3-phosphate dehydrogenase (GAPDH), $\beta$ 2-microglobulin, Hypoxanthine phosphoribosyltransferase-1, and large ribosomal protein-P0 and then compared to expression levels in unchallenged PDL cells and the healthy tissues (Livak et al., 2001).

Statistical analysis. The data were analyzed using the statistical software $\operatorname{SPSS}^{\circledR}$ v.22 (IBM, Armonk, NY, USA). Results were evaluated by a one-way ANOVA when comparing more than two groups, whereas the student's t-test was used when comparing two groups. $p \leq 0.05$ was considered significant, whereas $p \leq 0.001$ was considered highly significant.

This article is protected by copyright. All rights reserved. 


\section{Acknowledgements}

These studies were supported by an NIH grant (RO1 DE025225) to Yvonne L. Kapila and J. Christopher Fenno and a Fellowship from the Egyptian Ministry of Higher Education to Islam Ateia. We thank Hongriu Liu for technical assistance. The authors declare no conflict of interest.
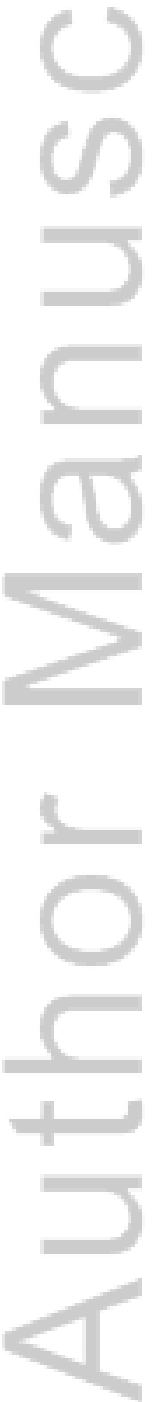

This article is protected by copyright. All rights reserved. 


\section{References}

Abdel Aziz, M.T., El-Asmar, M.F., El-Ibrashy, I.N., Rezq, A.M., Al-Malki, A.L., Wassef, M.A., et al. (2012). Effect of novel water soluble curcumin derivative on experimental type- 1 diabetes mellitus (short term study). Diabetol Metab Syndr 4, 30.

Achour, M., Mousli, M., Alhosin, M., Ibrahim, A., Peluso, J., Muller, C.D., et al. (2013). Epigallocatechin-3-gallate up-regulates tumor suppressor gene expression via a reactive oxygen species-dependent down-regulation of UHRF1. Biochem Biophys Res Commun 430, 208-212.

Ahn, M.Y., Kang, D.O., Na, Y.J., Yoon, S., Choi, W.S., Kang, K.W., et al. (2012). Histone deacetylase inhibitor, apicidin, inhibits human ovarian cancer cell migration via class II histone deacetylase 4 silencing. Cancer Lett 325, 189-199.

Ailenberg, M. and Silverman, M. (2002). Trichostatin A-histone deacetylase inhibitor with clinical therapeutic potential-is also a selective and potent inhibitor of gelatinase A expression. Biochem Biophys Res Commun 298, 110-115.

Andia, D.C., de Oliveira, N.F., Casarin, R.C., Casati, M.Z., Line, S.R. and de Souza, A.P. (2010). DNA methylation status of the IL8 gene promoter in aggressive periodontitis. $J$ Periodontol 81, 1336-1341.

Araki, Y., Tsuzuki Wada, T., Aizaki, Y., Sato, K., Yokota, K., Fujimoto, K., et al. (2016). Histone Methylation and STAT-3 Differentially Regulate Interleukin-6-Induced Matrix 
Metalloproteinase Gene Activation in Rheumatoid Arthritis Synovial Fibroblasts. Arthritis Rheumatol 68, 1111-1123.

Aresu, L., Benali, S., Garbisa, S., Gallo, E. and Castagnaro, M. (2011). Matrix metalloproteinases and their role in the renal epithelial mesenchymal transition. Histol Histopathol 26, 307-313.

Armitage, G.C. (2004). Periodontal diagnoses and classification of periodontal diseases. Periodontol 2000 34, 9-21.

Armitage, G.C. (2008). [Challenges in diagnosis and classification of periodontal diseases and conditions]. Zhonghua Kou Qiang Yi Xue Za Zhi 43, 260-263.

Asai, Y., Jinno, T., Igarashi, H., Ohyama, Y. and Ogawa, T. (2002). Detection and quantification of oral treponemes in subgingival plaque by real-time PCR. J Clin Microbiol 40, 33343340.

Azevedo, A., Prado, A.F., Antonio, R.C., Issa, J.P. and Gerlach, R.F. (2014). Matrix metalloproteinases are involved in cardiovascular diseases. Basic Clin Pharmacol Toxicol 115, 301-314.

Bakir, B., Yetkin Ay, Z., Buyukbayram, H.I., Kumbul Doguc, D., Bayram, D., Candan, I.A. and Uskun, E. (2016). The effect of curcumin treatment on systemic Th17 response; gingival expression of IL-17 and retinoic acid receptor-related orphan receptor $\gamma \mathrm{t}$; and alveolar bone loss in experimental periodontitis. J Periodontol, 1-17. 
Balasubramanyam, K., Varier, R.A., Altaf, M., Swaminathan, V., Siddappa, N.B., Ranga, U. and Kundu, T.K. (2004). Curcumin, a novel p300/CREB-binding protein-specific inhibitor of acetyltransferase, represses the acetylation of histone/nonhistone proteins and histone acetyltransferase-dependent chromatin transcription. J Biol Chem 279, 51163-51171.

Baliga, M.S., Joseph, N., Venkataranganna, M.V., Saxena, A., Ponemone, V. and Fayad, R. (2012). Curcumin, an active component of turmeric in the prevention and treatment of ulcerative colitis: preclinical and clinical observations. Food Funct 3, 1109-1117.

Barros, S.P. and Offenbacher, S. (2009). Epigenetics: connecting environment and genotype to phenotype and disease. J Dent Res 88, 400-408.

Barros, S.P. and Offenbacher, S. (2014). Modifiable risk factors in periodontal disease: epigenetic regulation of gene expression in the inflammatory response. Periodontol 2000 64, 95-110.

Barski, A., Cuddapah, S., Cui, K., Roh, T.Y., Schones, D.E., Wang, Z., et al. (2007). Highresolution profiling of histone methylations in the human genome. Cell 129, 823-837.

Bauden, M., Tassidis, H. and Ansari, D. (2015). In vitro cytotoxicity evaluation of HDAC inhibitor Apicidin in pancreatic carcinoma cells subsequent time and dose dependent treatment. Toxicol Lett 236, 8-15.

Bayarsaihan, D. (2011). Epigenetic mechanisms in inflammation. J Dent Res 90, 9-17.

Bayarsaihan, D. (2016). Epigenetic mechanisms involved in modulation of inflammatory diseases. Curr Opin Clin Nutr Metab Care 19, 263-269. 
Bird, A. (2002). DNA methylation patterns and epigenetic memory. Genes Dev 16, 6-21.

Borkham-Kamphorst, E., Alexi, P., Tihaa, L., Haas, U. and Weiskirchen, R. (2015). Plateletderived growth factor-D modulates extracellular matrix homeostasis and remodeling through TIMP-1 induction and attenuation of MMP-2 and MMP-9 gelatinase activities. Biochem Biophys Res Commun 457, 307-313.

Brew, K. and Nagase, H. (2010). The tissue inhibitors of metalloproteinases (TIMPs): an ancient family with structural and functional diversity. Biochim Biophys Acta 1803, 55-71.

Butler, G.S., Butler, M.J., Atkinson, S.J., Will, H., Tamura, T., Schade van Westrum, S., et al. (1998). The TIMP2 membrane type 1 metalloproteinase "receptor" regulates the concentration and efficient activation of progelatinase A. A kinetic study. J Biol Chem 273, 871-880.

Cao, F., Liu, T., Xu, Y., Xu, D. and Feng, S. (2015). Curcumin inhibits cell proliferation and promotes apoptosis in human osteoclastoma cell through MMP-9, NF-kappaB and JNK signaling pathways. Int J Clin Exp Pathol 8, 6037-6045.

Chang, C.W., Hsieh, Y.H., Yang, W.E., Yang, S.F., Chen, Y. and Hu, D.N. (2014a). Epigallocatechingallate inhibits migration of human uveal melanoma cells via downregulation of matrix metalloproteinase-2 activity and ERK1/2 pathway. Biomed Res Int 2014, 141582.

Chang, H.W., Wang, H.C., Chen, C.Y., Hung, T.W., Hou, M.F., Yuan, S.S., et al. (2014b). 5azacytidine induces anoikis, inhibits mammosphere formation and reduces 
metalloproteinase 9 activity in MCF-7 human breast cancer cells. Molecules 19, 31493159.

Chang, J., Varghese, D.S., Gillam, M.C., Peyton, M., Modi, B., Schiltz, R.L., et al. (2012). Differential response of cancer cells to HDAC inhibitors trichostatin A and depsipeptide. Br J Cancer 106, 116-125.

Chang, Y.C., Yang, S.F., Lai, C.C., Liu, J.Y. and Hsieh, Y.S. (2002). Regulation of matrix metalloproteinase production by cytokines, pharmacological agents and periodontal pathogens in human periodontal ligament fibroblast cultures. J Periodontal Res 37, 196203.

Charitaki, E., Kastritis, E., Petraki, C., Liapis, K., Adamidis, K., Apostolou, T., et al. (2016). Glomerular expression of matrix metalloproteinases in AL-amyloidosis and association with renal function at the time of kidney biopsy. Clin Nephrol 85, 44-54.

Chen, W.F., Huang, F. and Zha, J. (2012). [The comparison of short-term efficacies between decitabine and HA regimen for MDS/AML patients]. Zhonghua Хие Ye Xие Za Zhi 33, $143-144$.

Chernov, A.V., Sounni, N.E., Remacle, A.G. and Strongin, A.Y. (2009). Epigenetic control of the invasion-promoting MT1-MMP/MMP-2/TIMP-2 axis in cancer cells. J Biol Chem 284, 12727-12734.

Chi, B., Qi, M. and Kuramitsu, H.K. (2003). Role of dentilisin in Treponema denticola epithelial cell layer penetration. Res Microbiol 154, 637-643.

This article is protected by copyright. All rights reserved. 
Choi, B.K., Jung, J.H., Suh, H.Y., Yoo, Y.J., Cho, K.S., Chai, J.K. and Kim, C.K. (2001). Activation of matrix metalloproteinase-2 by a novel oral spirochetal species Treponema lecithinolyticum. J Periodontol 72, 1594-1600.

Choi, B.K., Paster, B.J., Dewhirst, F.E. and Gobel, U.B. (1994). Diversity of cultivable and uncultivable oral spirochetes from a patient with severe destructive periodontitis. Infect Immun 62, 1889-1895.

Dai, R., Iwama, A., Wang, S. and Kapila, Y.L. (2005). Disease-associated fibronectin matrix fragments trigger anoikis of human primary ligament cells: p53 and c-myc are suppressed. Apoptosis 10, 503-512.

de Camargo Pereira, G., Guimaraes, G.N., Planello, A.C., Santamaria, M.P., de Souza, A.P., Line, S.R. and Marques, M.R. (2013). Porphyromonas gingivalis LPS stimulation downregulates DNMT1, DNMT3a, and JMJD3 gene expression levels in human HaCaT keratinocytes. Clin Oral Investig 17, 1279-1285.

Ding, Y., Haapasalo, M., Kerosuo, E., Lounatmaa, K., Kotiranta, A. and Sorsa, T. (1997). Release and activation of human neutrophil matrix metallo- and serine proteinases during phagocytosis of Fusobacterium nucleatum, Porphyromonas gingivalis and Treponema denticola. J Clin Periodontol 24, 237-248.

Du, A., Zhao, S., Wan, L., Liu, T., Peng, Z., Zhou, Z., et al. (2016). MicroRNA expression profile of human periodontal ligament cells under the influence of Porphyromonas gingivalis LPS. J Cell Mol Med 20, 1329-1338.

This article is protected by copyright. All rights reserved. 
Ejeil, A.L., Igondjo-Tchen, S., Ghomrasseni, S., Pellat, B., Godeau, G. and Gogly, B. (2003). Expression of matrix metalloproteinases (MMPs) and tissue inhibitors of metalloproteinases (TIMPs) in healthy and diseased human gingiva. J Periodontol 74, $188-195$.

Elburki, M.S., Moore, D.D., Terezakis, N.G., Zhang, Y., Lee, H.M., Johnson, F. and Golub, L.M. (2016). A novel chemically modified curcumin reduces inflammation-mediated connective tissue breakdown in a rat model of diabetes: periodontal and systemic effects. J Periodontal Res.

Elburki, M.S., Rossa, C., Guimaraes, M.R., Goodenough, M., Lee, H.M., Curylofo, F.A., et al. (2014). A novel chemically modified curcumin reduces severity of experimental periodontal disease in rats: initial observations. Mediators Inflamm 2014, 959471.

Ellen, R.P., Dawson, J.R. and Yang, P.F. (1994). Treponema denticola as a model for polar adhesion and cytopathogenicity of spirochetes. Trends Microbiol 2, 114-119.

Ellen, R.P. and Galimanas, V.B. (2005). Spirochetes at the forefront of periodontal infections. Periodontol 2000 38, 13-32.

Endres, M., Kneitz, S., Orth, M.F., Perera, R.K., Zernecke, A. and Butt, E. (2016). Regulation of matrix metalloproteinases (MMPs) expression and secretion in MDA-MB-231 breast cancer cells by LIM and SH3 protein 1 (LASP1). Oncotarget.

This article is protected by copyright. All rights reserved. 
Feng, Q., Su, Z., Song, S., Chiu, H., Zhang, B., Yi, L., et al. (2016). Histone deacetylase inhibitors suppress RSV infection and alleviate virus-induced airway inflammation. Int J Mol Med.

Fenno, J.C. (2005). Laboratory maintenance of Treponema denticola. Curr Protoc Microbiol Chapter 12, Unit 12B 11.

Fenno, J.C., Hannam, P.M., Leung, W.K., Tamura, M., Uitto, V.J. and McBride, B.C. (1998). Cytopathic effects of the major surface protein and the chymotrypsinlike protease of Treponema denticola. Infect Immun 66, 1869-1877.

Garcia, D., Tarima, S. and Okunseri, C. (2015). Periodontitis and glycemic control in diabetes: NHANES 2009 to 2012. J Periodontol 86, 499-506.

Ghosh, A., Park, J.Y., Fenno, C. and Kapila, Y.L. (2008). Porphyromonas gingivalis, gamma interferon, and a proapoptotic fibronectin matrix form a synergistic trio that induces c-Jun N-terminal kinase 1-mediated nitric oxide generation and cell death. Infect Immun 76, 5514-5523.

Goldberg, A.D., Allis, C.D. and Bernstein, E. (2007). Epigenetics: a landscape takes shape. Cell 128, 635-638.

Grenier, D., Uitto, V.J. and McBride, B.C. (1990). Cellular location of a Treponema denticola chymotrypsinlike protease and importance of the protease in migration through the basement membrane. Infect Immun 58, 347-351.

This article is protected by copyright. All rights reserved. 
Guenther, M.G., Levine, S.S., Boyer, L.A., Jaenisch, R. and Young, R.A. (2007). A chromatin landmark and transcription initiation at most promoters in human cells. Cell 130, 77-88.

Haapasalo, M., Singh, U., McBride, B.C. and Uitto, V.J. (1991). Sulfhydryl-dependent attachment of Treponema denticola to laminin and other proteins. Infect Immun 59, 42304237.

Hassler, M.R., Klisaroska, A., Kollmann, K., Steiner, I., Bilban, M., Schiefer, A.I., et al. (2012). Antineoplastic activity of the DNA methyltransferase inhibitor 5-aza-2'-deoxycytidine in anaplastic large cell lymphoma. Biochimie 94, 2297-2307.

Herceg, Z. (2016). Epigenetic Mechanisms as an Interface Between the Environment and Genome. Adv Exp Med Biol 903, 3-15.

Hernandez-Barrantes, S., Shimura, Y., Soloway, P.D., Sang, Q.A. and Fridman, R. (2001). Differential roles of TIMP-4 and TIMP-2 in pro-MMP-2 activation by MT1-MMP. Biochem Biophys Res Commun 281, 126-130.

Hook, K.E., Garza, S.J., Lira, M.E., Ching, K.A., Lee, N.V., Cao, J., et al. (2012). An integrated genomic approach to identify predictive biomarkers of response to the aurora kinase inhibitor PF-03814735. Mol Cancer Ther 11, 710-719.

Huynh, Q.N., Wang, S., Tafolla, E., Gansky, S.A., Kapila, S., Armitage, G.C. and Kapila, Y.L. (2002). Specific fibronectin fragments as markers of periodontal disease status. $J$ Periodontol 73, 1101-1110. 
Inagaki, S., Kimizuka, R., Kokubu, E., Saito, A. and Ishihara, K. (2016). Treponema denticola invasion into human gingival epithelial cells. Microb Pathog 94, 104-111.

Jani, J.P., Arcari, J., Bernardo, V., Bhattacharya, S.K., Briere, D., Cohen, B.D., et al. (2010). PF03814735, an orally bioavailable small molecule aurora kinase inhibitor for cancer therapy. Mol Cancer Ther 9, 883-894.

Jee, S.W., Wang, S. and Kapila, Y.L. (2004). Specific pro-apoptotic fibronectin fragments modulate proteinase expression in periodontal ligament cells. J Periodontol 75, 523-530.

Jenuwein, T. and Allis, C.D. (2001). Translating the histone code. Science 293, 1074-1080.

Jo, A.R., Baek, K.J., Shin, J.E. and Choi, Y. (2014). Mechanisms of IL-8 suppression by Treponema denticola in gingival epithelial cells. Immunol Cell Biol 92, 139-147.

Joo, N.E., Watanabe, T., Chen, C., Chekenya, M., Stallcup, W.B. and Kapila, Y.L. (2008). NG2, a novel proapoptotic receptor, opposes integrin alpha4 to mediate anoikis through PKCalpha-dependent suppression of FAK phosphorylation. Cell Death Differ 15, 899907.

Joseph, J., Kapila, Y.L., Hayami, T. and Kapila, S. (2010). Disease-associated extracellular matrix suppresses osteoblastic differentiation of human periodontal ligament cells via MMP-1. Calcif Tissue Int 86, 154-162.

Kapila, Y.L., Kapila, S. and Johnson, P.W. (1996). Fibronectin and fibronectin fragments modulate the expression of proteinases and proteinase inhibitors in human periodontal ligament cells. Matrix Biol 15, 251-261. 
Kapila, Y.L., Lancero, H. and Johnson, P.W. (1998). The response of periodontal ligament cells to fibronectin. J Periodontol 69, 1008-1019.

Kapila, Y.L., Wang, S., Dazin, P., Tafolla, E. and Mass, M.J. (2002). The heparin-binding domain and $\mathrm{V}$ region of fibronectin regulate apoptosis by suppression of p53 and c-myc in human primary cells. J Biol Chem 277, 8482-8491.

Kapila, Y.L., Wang, S. and Johnson, P.W. (1999). Mutations in the heparin binding domain of fibronectin in cooperation with the $\mathrm{V}$ region induce decreases in pp125(FAK) levels plus proteoglycan-mediated apoptosis via caspases. J Biol Chem 274, 30906-30913.

Khansari, N., Shakiba, Y. and Mahmoudi, M. (2009). Chronic inflammation and oxidative stress as a major cause of age-related diseases and cancer. Recent Pat Inflamm Allergy Drug Discov 3, 73-80.

Kim, M.S., Son, M.W., Kim, W.B., In Park, Y. and Moon, A. (2000). Apicidin, an inhibitor of histone deacetylase, prevents H-ras-induced invasive phenotype. Cancer Lett 157, 23-30.

Kinoshita, T., Sato, H., Okada, A., Ohuchi, E., Imai, K., Okada, Y. and Seiki, M. (1998). TIMP2 promotes activation of progelatinase A by membrane-type 1 matrix metalloproteinase immobilized on agarose beads. J Biol Chem 273, 16098-16103.

Koch, C.M., Andrews, R.M., Flicek, P., Dillon, S.C., Karaoz, U., Clelland, G.K., et al. (2007). The landscape of histone modifications across $1 \%$ of the human genome in five human cell lines. Genome Res 17, 691-707. 
Konermann, A., Deschner, J., Allam, J.P., Novak, N., Winter, J., Baader, S.L., et al. (2012). Antigen-presenting cell marker expression and phagocytotic activity in periodontal ligament cells. J Oral Pathol Med 41, 340-347.

Kouzarides, T. (2007). Chromatin modifications and their function. Cell 128, 693-705.

Kubicek, S., O'Sullivan, R.J., August, E.M., Hickey, E.R., Zhang, Q., Teodoro, M.L., et al. (2007). Reversal of H3K9me2 by a small-molecule inhibitor for the G9a histone methyltransferase. Mol Cell 25, 473-481.

Lamont, R.J., Chan, A., Belton, C.M., Izutsu, K.T., Vasel, D. and Weinberg, A. (1995). Porphyromonas gingivalis invasion of gingival epithelial cells. Infect Immun 63, 38783885 .

Lee, A.Y., Fan, C.C., Chen, Y.A., Cheng, C.W., Sung, Y.J., Hsu, C.P. and Kao, T.Y. (2015). Curcumin inhibits invasiveness and epithelial-mesenchymal transition in oral squamous cell carcinoma through reducing matrix metalloproteinase 2, 9 and modulating p53-Ecadherin pathway. Integr Cancer Ther 14, 484-490.

Leira, Y., Seoane, J., Blanco, M., Rodriguez-Yanez, M., Takkouche, B., Blanco, J. and Castillo, J. (2016). Association between periodontitis and ischemic stroke: a systematic review and meta-analysis. Eur J Epidemiol.

Ligi, D. and Mannello, F. (2016). Do matrix metalloproteinases represent reliable circulating biomarkers in colorectal cancer? Br J Cancer 115, 633-634. 
Liu, C.C., Chang, T.C., Lin, Y.T., Yu, Y.L., Ko, B.S., Sung, L.Y. and Liou, J.Y. (2016). Paracrine regulation of matrix metalloproteinases contributes to cancer cell invasion by hepatocellular carcinoma-secreted 14-3-3sigma. Oncotarget.

Liu, W.H., Sang, M.X., Hou, S.Y., Zhang, C. and Shan, B.E. (2014). Low-dose decitabine induces MAGE-A expression and inhibits invasion via suppression of NF-kappaB2 and MMP2 in Eca109 cells. Biomed Pharmacother 68, 745-750.

Liu, Z., Zhang, L., Ding, F., Li, J., Guo, M., Li, W., et al. (2005). 5-Aza-2'-deoxycytidine induces retinoic acid receptor-beta(2) demethylation and growth inhibition in esophageal squamous carcinoma cells. Cancer Lett 230, 271-283.

Livak, K.J. and Schmittgen, T.D. (2001). Analysis of relative gene expression data using realtime quantitative PCR and the 2(-Delta Delta C(T)) Method. Methods 25, 402-408.

Lukaszewicz-Zajac, M., Szmitkowski, M., Litman-Zawadzka, A. and Mroczko, B. (2016). Matrix Metalloproteinases and Their Tissue Inhibitors in Comparison to Other Inflammatory Proteins in Gastric Cancer (GC). Cancer Invest 34, 305-312.

Madsen, D.H., Jurgensen, H.J., Ingvarsen, S., Melander, M.C., Albrechtsen, R., Hald, A., et al. (2013). Differential actions of the endocytic collagen receptor uPARAP/Endo180 and the collagenase MMP-2 in bone homeostasis. PLoS One 8, e71261.

Makinen, P.L., Makinen, K.K. and Syed, S.A. (1995). Role of the chymotrypsin-like membraneassociated proteinase from Treponema denticola ATCC 35405 in inactivation of bioactive peptides. Infect Immun 63, 3567-3575.

This article is protected by copyright. All rights reserved. 
Mani, S.K., Kern, C.B., Kimbrough, D., Addy, B., Kasiganesan, H., Rivers, W.T., et al. (2015). Inhibition of class I histone deacetylase activity represses matrix metalloproteinase-2 and -9 expression and preserves LV function postmyocardial infarction. Am J Physiol Heart Circ Physiol 308, H1391-1401.

Martinez, J.A., Milagro, F.I., Claycombe, K.J. and Schalinske, K.L. (2014). Epigenetics in adipose tissue, obesity, weight loss, and diabetes. Adv Nutr 5, 71-81.

Mathers, D.A., Leung, W.K., Fenno, J.C., Hong, Y. and McBride, B.C. (1996). The major surface protein complex of Treponema denticola depolarizes and induces ion channels in HeLa cell membranes. Infect Immun 64, 2904-2910.

McDowell, J.V., Frederick, J., Miller, D.P., Goetting-Minesky, M.P., Goodman, H., Fenno, J.C. and Marconi, R.T. (2011). Identification of the primary mechanism of complement evasion by the periodontal pathogen, Treponema denticola. Mol Oral Microbiol 26, 140-

\section{9.}

McDowell, J.V., Huang, B., Fenno, J.C. and Marconi, R.T. (2009). Analysis of a unique interaction between the complement regulatory protein factor $\mathrm{H}$ and the periodontal pathogen Treponema denticola. Infect Immun 77, 1417-1425.

Medina, C., Santana, A., Quintero, E., Radomski, M.W. and Guarner, F. (2004). [Matrix metalloproteinases in diseases of the gastrointestinal tract]. Gastroenterol Hepatol 27, 491-497. 
Medzhitov, R. and Horng, T. (2009). Transcriptional control of the inflammatory response. Nat Rev Immunol 9, 692-703.

Miao, D., Fenno, J.C., Timm, J.C., Joo, N.E. and Kapila, Y.L. (2011). The Treponema denticola chymotrypsin-like protease dentilisin induces matrix metalloproteinase-2-dependent fibronectin fragmentation in periodontal ligament cells. Infect Immun 79, 806-811.

Miao, D., Godovikova, V., Qian, X., Seshadrinathan, S., Kapila, Y.L. and Fenno, J.C. (2014). Treponema denticola upregulates MMP-2 activation in periodontal ligament cells: interplay between epigenetics and periodontal infection. Arch Oral Biol 59, 1056-1064.

Mirza, S., Sharma, G., Pandya, P. and Ralhan, R. (2010). Demethylating agent 5-aza-2deoxycytidine enhances susceptibility of breast cancer cells to anticancer agents. Mol Cell Biochem 342, 101-109.

Mittal, R., Patel, A.P., Debs, L.H., Nguyen, D., Patel, K., Grati, M., et al. (2016). Intricate Functions of Matrix Metalloproteinases in Physiological and Pathological Conditions. $J$ Cell Physiol 231, 2599-2621.

Mogal, A. and Abdulkadir, S.A. (2006). Effects of Histone Deacetylase Inhibitor (HDACi); Trichostatin-A (TSA) on the expression of housekeeping genes. Mol Cell Probes 20, 8186.

Mosig, R.A. and Martignetti, J.A. (2013). Loss of MMP-2 in murine osteoblasts upregulates osteopontin and bone sialoprotein expression in a circuit regulating bone homeostasis. Dis Model Mech 6, 397-403.

This article is protected by copyright. All rights reserved. 
Murphy, G., Stanton, H., Cowell, S., Butler, G., Knauper, V., Atkinson, S. and Gavrilovic, J. (1999). Mechanisms for pro matrix metalloproteinase activation. APMIS 107, 38-44.

Nagaraju, G.P., Aliya, S., Zafar, S.F., Basha, R., Diaz, R. and El-Rayes, B.F. (2012). The impact of curcumin on breast cancer. Integr Biol (Camb) 4, 996-1007.

Nagase, H. (1997). Activation mechanisms of matrix metalloproteinases. Biol Chem 378, 151160.

Nagase, H., Visse, R. and Murphy, G. (2006). Structure and function of matrix metalloproteinases and TIMPs. Cardiovasc Res 69, 562-573.

Nagasri, M., Madhulatha, M., Musalaiah, S.V., Kumar, P.A., Krishna, C.H. and Kumar, P.M. (2015). Efficacy of curcumin as an adjunct to scaling and root planning in chronic periodontitis patients: A clinical and microbiological study. J Pharm Bioallied Sci 7, S554-558.

Nakayama, J., Rice, J.C., Strahl, B.D., Allis, C.D. and Grewal, S.I. (2001). Role of histone H3 lysine 9 methylation in epigenetic control of heterochromatin assembly. Science 292, $110-113$.

Navratilova, Z., Kolek, V. and Petrek, M. (2016). Matrix metalloproteinases and their inhibitors in chronic obstructive pulmonary disease. Arch Immunol Ther Exp (Warsz) 64, 177-193.

Nebbioso, A., Carafa, V., Benedetti, R. and Altucci, L. (2012). Trials with 'epigenetic' drugs: an update. Mol Oncol 6, 657-682.

This article is protected by copyright. All rights reserved. 
Niller, H.H., Masa, R., Venkei, A., Meszaros, S. and Minarovits, J. (2017). Pathogenic mechanisms of intracellular bacteria. Curr Opin Infect Dis 30, 309-315.

Nissinen, L. and Kahari, V.M. (2014). Matrix metalloproteinases in inflammation. Biochim Biophys Acta 1840, 2571-2580.

Nowakowska, A. and Tarasiuk, J. (2016). Comparative effects of selected plant polyphenols, gallic acid and epigallocatechin gallate, on matrix metalloproteinases activity in multidrug resistant MCF7/DOX breast cancer cells. Acta Biochim Pol.

Offenbacher, S., Barros, S.P. and Beck, J.D. (2008). Rethinking periodontal inflammation. $J$ Periodontol 79, 1577-1584.

Oyarzun, A., Arancibia, R., Hidalgo, R., Penafiel, C., Caceres, M., Gonzalez, M.J., et al. (2010). Involvement of MT1-MMP and TIMP-2 in human periodontal disease. Oral Dis 16, 388395.

Pardo, A., Cabrera, S., Maldonado, M. and Selman, M. (2016). Role of matrix metalloproteinases in the pathogenesis of idiopathic pulmonary fibrosis. Respir Res 17, 23.

Park, S.Y., Jun, J.A., Jeong, K.J., Heo, H.J., Sohn, J.S., Lee, H.Y., et al. (2011). Histone deacetylases 1, 6 and 8 are critical for invasion in breast cancer. Oncol Rep 25, 16771681.

Pasquier, J., Hoarau-Vechot, J., Fakhro, K., Rafii, A. and Abi Khalil, C. (2015). Epigenetics and Cardiovascular Disease in Diabetes. Curr Diab Rep 15, 108.

This article is protected by copyright. All rights reserved. 
Pereira, I.T., Ramos, E.A., Costa, E.T., Camargo, A.A., Manica, G.C., Klassen, L.M., et al. (2014). Fibronectin affects transient MMP2 gene expression through DNA demethylation changes in non-invasive breast cancer cell lines. PLoS One 9, e105806.

Perkins, D.J., Patel, M.C., Blanco, J.C. and Vogel, S.N. (2016). Epigenetic mechanisms governing innate inflammatory responses. J Interferon Cytokine Res 36, 454-461.

Pietruszewska, W., Bojanowska-Pozniak, K. and Kobos, J. (2016). Matrix metalloproteinases MMP1, MMP2, MMP9 and their tissue inhibitors TIMP1, TIMP2, TIMP3 in head and neck cancer: an immunohistochemical study. Otolaryngol Pol 70, 32-43.

Pihlstrom, B.L., Michalowicz, B.S. and Johnson, N.W. (2005). Periodontal diseases. The Lancet 366, 1809-1820.

Prasanna, S.J. (2011). Causal relationship between periodontitis and chronic obstructive pulmonary disease. J Indian Soc Periodontol 15, 359-365.

Razzouk, S. and Sarkis, R. (2013). Smoking and diabetes. Epigenetics involvement in osseointegration. N Y State Dent J 79, 27-30.

Safronova, O. and Morita, I. (2010). Transcriptome remodeling in hypoxic inflammation. J Dent Res 89, 430-444.

Sakamoto, M., Takeuchi, Y., Umeda, M., Ishikawa, I. and Benno, Y. (2001). Rapid detection and quantification of five periodontopathic bacteria by real-time PCR. Microbiol Immunol 45, $39-44$.

This article is protected by copyright. All rights reserved. 
Saldanha, S.N., Kala, R. and Tollefsbol, T.O. (2014). Molecular mechanisms for inhibition of colon cancer cells by combined epigenetic-modulating epigallocatechin gallate and sodium butyrate. Exp Cell Res 324, 40-53.

Scanlon, C., Marchesan, J., Soehren, S., Matsuo, M. and Kapila, Y. (2011). Capturing the regenerative potential of periodontal ligament fibroblasts. J Stem Cells Regen Med 7, 5456.

Schoffski, P., Jones, S.F., Dumez, H., Infante, J.R., Van Mieghem, E., Fowst, C., et al. (2011). Phase I, open-label, multicentre, dose-escalation, pharmacokinetic and pharmacodynamic trial of the oral aurora kinase inhibitor PF-03814735 in advanced solid tumours. Eur $J$ Cancer 47, 2256-2264.

Shin, J. and Choi, Y. (2012). The fate of Treponema denticola within human gingival epithelial cells. Mol Oral Microbiol 27, 471-482.

Shinkarenko, T.V., Rumiantsev, V.A., Egorova, E.N. and Eliseeva, T.I. (2013). [Matrix metalloproteinases in periodontitis]. Stomatologiia (Mosk) 92, 77-80.

Shofuda, K., Moriyama, K., Nishihashi, A., Higashi, S., Mizushima, H., Yasumitsu, H., et al. (1998). Role of tissue inhibitor of metalloproteinases-2 (TIMP-2) in regulation of progelatinase A activation catalyzed by membrane-type matrix metalloproteinase-1 (MT1MMP) in human cancer cells. $J$ Biochem 124, 462-470.

Simonson, L.G., Goodman, C.H., Bial, J.J. and Morton, H.E. (1988). Quantitative relationship of Treponema denticola to severity of periodontal disease. Infect Immun 56, 726-728. 
Sitholimela, C.S. and Shangase, L.S. (2013). The association between periodontitis and pre-term birth and/or low birth weight: a literature review. SADJ 68, 162-166.

Socransky, S.S., Haffajee, A.D., Cugini, M.A., Smith, C. and Kent, R.L., Jr. (1998). Microbial complexes in subgingival plaque. J Clin Periodontol 25, 134-144.

Song, S.E., Choi, B.K., Kim, S.N., Yoo, Y.J., Kim, M.M., Park, S.K., et al. (2003). Inhibitory effect of procyanidin oligomer from elm cortex on the matrix metalloproteinases and proteases of periodontopathogens. J Periodontal Res 38, 282-289.

Stewart, R. and West, M. (2016). Increasing evidence for an association between periodontitis and cardiovascular disease. Circulation 133, 549-551.

Strongin, A.Y., Collier, I., Bannikov, G., Marmer, B.L., Grant, G.A. and Goldberg, G.I. (1995). Mechanism of cell surface activation of 72-kDa type IV collagenase. Isolation of the activated form of the membrane metalloprotease. J Biol Chem 270, 5331-5338.

Tafolla, E., Wang, S., Wong, B., Leong, J. and Kapila, Y.L. (2005). JNK1 and JNK2 oppositely regulate p53 in signaling linked to apoptosis triggered by an altered fibronectin matrix: JNK links FAK and p53. J Biol Chem 280, 19992-19999.

Talbert, P.B. and Henikoff, S. (2006). Spreading of silent chromatin: inaction at a distance. Nat Rev Genet 7, 793-803.

Tanaka, K., Iwasaki, K., Feghali, K.E., Komaki, M., Ishikawa, I. and Izumi, Y. (2011). Comparison of characteristics of periodontal ligament cells obtained from outgrowth and enzyme-digested culture methods. Arch Oral Biol 56, 380-388. 
Uitto, V.J., Grenier, D., Chan, E.C. and McBride, B.C. (1988). Isolation of a chymotrypsinlike enzyme from Treponema denticola. Infect Immun 56, 2717-2722.

Veeraraghavan, J., Natarajan, M., Lagisetty, P., Awasthi, V., Herman, T.S. and Aravindan, N. (2011). Impact of curcumin, raspberry extract, and neem leaf extract on rel proteinregulated cell death/radiosensitization in pancreatic cancer cells. Pancreas 40, 11071119.

Waddington, C.H. (2012). The epigenotype. 1942. Int J Epidemiol 41, 10-13.

Wang, F., Qi, Y., Li, X., He, W., Fan, Q.X. and Zong, H. (2013). HDAC inhibitor trichostatin A suppresses esophageal squamous cell carcinoma metastasis through HADC2 reduced MMP-2/9. Clin Invest Med 36, E87-94.

Williams, R.C., Barnett, A.H., Claffey, N., Davis, M., Gadsby, R., Kellett, M., et al. (2008). The potential impact of periodontal disease on general health: a consensus view. Curr Med Res Opin 24, 1635-1643.

Yin, L. and Chung, W.O. (2011). Epigenetic regulation of human beta-defensin 2 and CC chemokine ligand 20 expression in gingival epithelial cells in response to oral bacteria. Mucosal Immunol 4, 409-419.

Yoshida, A., Kawada, M., Suzuki, N., Nakano, Y., Oho, T., Saito, T. and Yamashita, Y. (2004). TaqMan real-time polymerase chain reaction assay for the correlation of Treponema denticola numbers with the severity of periodontal disease. Oral Microbiol Immunol 19, 196-200. 
Zhang, M., Xiao, X.Q., Jiang, Y.F., Liang, Y.S., Peng, M.Y., Xu, Y. and Gong, G.Z. (2011). DNA demethylation in PD-1 gene promoter induced by 5-azacytidine activates PD-1 expression on Molt-4 cells. Cell Immunol 271, 450-454.

Zhang, S., Barros, S.P., Niculescu, M.D., Moretti, A.J., Preisser, J.S. and Offenbacher, S. (2010). Alteration of PTGS2 promoter methylation in chronic periodontitis. J Dent Res 89, 133137.

Zhang, Y. and Reinberg, D. (2001). Transcription regulation by histone methylation: interplay between different covalent modifications of the core histone tails. Genes Dev 15, 23432360.

Zucker, S., Pei, D., Cao, J. and Lopez-Otin, C. (2003). Membrane type-matrix metalloproteinases (MT-MMP). Curr Top Dev Biol 54, 1-74.

This article is protected by copyright. All rights reserved. 
Table 1. Chemical agents used to target chromatin modification enzymes.

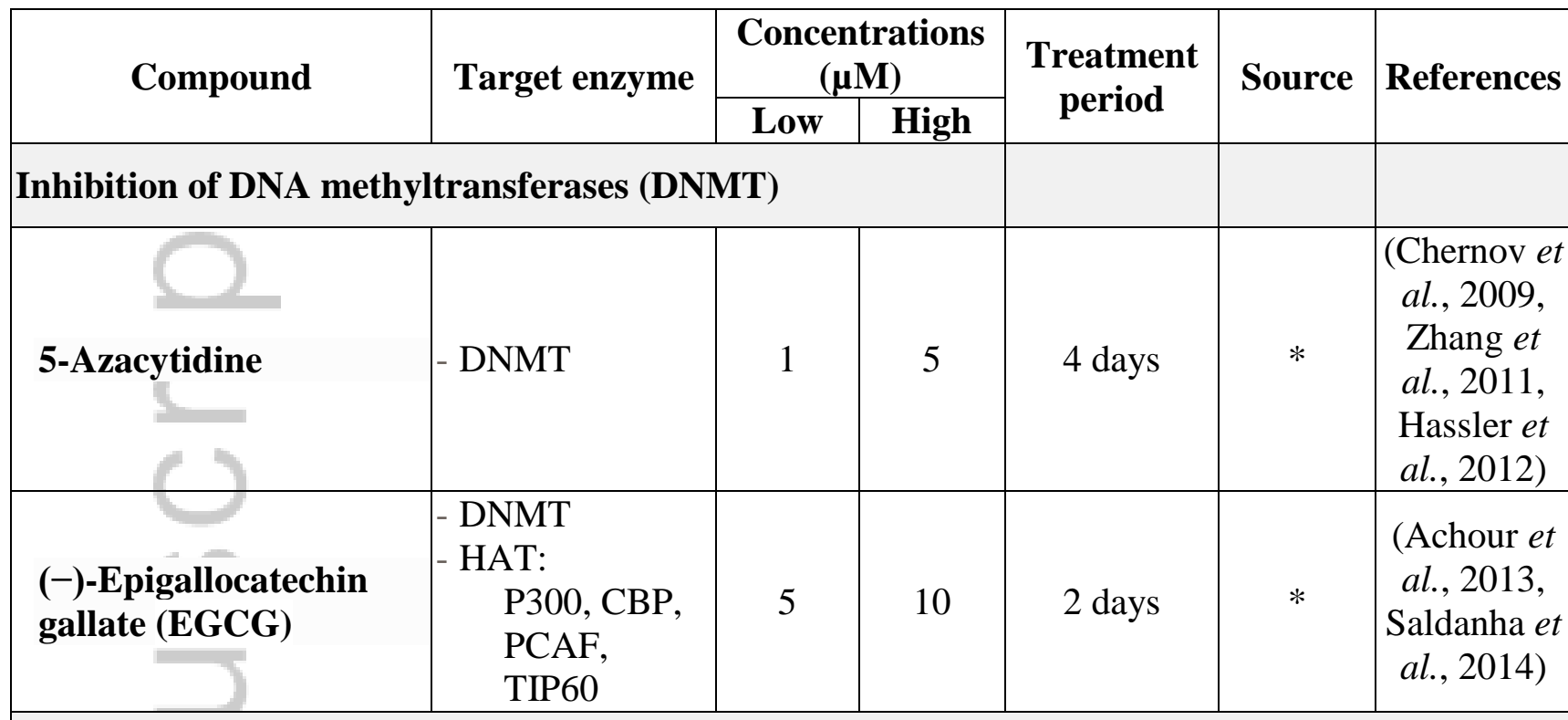

Inhibition of Histone Deacetylases (HDACs)

\begin{tabular}{|l|l|l|l|l|l|l|}
\hline Trichostatin A & - HDAC & 0.05 & 0.1 & 4 days & $*$ & $\begin{array}{c}\text { (Mogal } \text { et } \\
\text { al., 2006, } \\
\text { Chang } e t \\
\text { al. } 2012)\end{array}$ \\
\hline Apicidin & - HDAC & 0.5 & 1 & 1 day & $*$ & $\begin{array}{c}\text { Ahn } \text { et al., } \\
2012, \\
\text { Bauden } e t \\
\text { al., 2015) }\end{array}$ \\
\hline
\end{tabular}

Inhibition of Histone phosphorylation

\begin{tabular}{|l|l|c|c|c|c|c|}
\hline PF-03814735 & - AURK A & & & $*$ & $\begin{array}{c}\text { (Hook } \text { et } \\
\text { al., 2012) }\end{array}$ \\
\hline Inhibition of Histone Acetyltransferases (HATs) & 0.25 & 0.5 & 2 days & & & \\
\hline Curcumin & - HATs & 25 & 50 & 2 hours & $* \begin{array}{c}\text { (Balasubr } \\
\text { amanyam } \\
\text { et al., } \\
\text { 2004, Ahn } \\
\text { et al. },\end{array}$ \\
\hline
\end{tabular}

This article is protected by copyright. All rights reserved. 


\begin{tabular}{|l|l|c|c|c|c|c|}
\hline & & & & & $2012)$ \\
\hline Inhibition of Histone Methyltransferases (HMTs) & & & \\
\hline BIX 01294 & - HMT G9a & 0.5 & 1 & 2 days & $*$ & $\begin{array}{c}\text { (Kubicek } \text { et } \\
\text { al., 2007) }\end{array}$ \\
\hline Inhibition of Histone Demethylases (HDMs) \\
\begin{tabular}{l|l|l|l|l|l|} 
Tranylcypromine, HCl \\
(TCP)
\end{tabular} & $\begin{array}{c}\text { Monoamine } \\
\text { oxidase A/B } \\
\text { Histone LSD1/2 }\end{array}$ & 2 & 5 & 4 days & $\#$ & $\begin{array}{c}\text { (Nebbioso } \\
\text { t al., 2012) }\end{array}$ \\
\hline
\end{tabular}

* Sigma-Aldrich, St. Louis, MO, USA

\# EMD Millipore, Temecula, CA, USA

This article is protected by copyright. All rights reserved. 


\section{FIGURE LEGENDS}

Figure 1. T. denticola mediates chronic expression and activation of MMP-2, MT1-MMP, and TIMP-2 in PDL cells, with subsequent fragmentation of cellular fibronectin. Cultured PDL cells were challenged with $T$. denticola $(T d)$ at MOI $=100$ or media control for two hours, then incubated for 3, 6, 9, and 12 days with daily medium changes. The experiments were repeated three times in triplicate. Data were analyzed using one-way ANOVA. $(*)$ represents $p \leq$ 0.05 compared to the same time point in the control group. (\#) represents $p \leq 0.001$ compared to the same time point in the control group.

Panel A: A representative gelatin zymogram of PDL cell conditioned medium showing the gelatinolytic activity of pro-MMP-2 (72-kDa), active MMP-2 (64-kDa), and Td dentilisin (100-

$\mathrm{kDa}$ ). The left 4 lanes represent the control unchallenged PDL cells and the right 4 lanes represent the $T d$-challenged PDL cells. The bar chart below represents the densitometric analysis of gelatinolytic activity in the zymograms using Image ${ }^{\mathrm{TM}_{-}}-\mathrm{NIH}$ software. The Y-axis represents fold-gelatinolytic activity of the pro-MMP-2, active MMP-2, and dentilisin relative to unchallenged control at day 3 . The $\mathrm{X}$-axis represents different time points.

Panel B: A representative immunoblot of PDL cell culture supernatants probed with a polyclonal anti-fibronectin antibody showing $\mathrm{FN}$ fragmentation in conditioned medium from $T d$-challenged PDL cells. 
Panel C: Transcript levels of MMP-2, MT1-MMP, and TIMP-2 in PDL cells at different time points after challenge with $T d$ or media control assayed by qRT-PCR. The Y-axis represents fold-expression level of each gene relative to unchallenged control at day 3. The X-axis represents different time points.

Figure 2. Elevated MMP-2 mRNA and T. denticola in diseased periodontal tissue. Levels of T. denticola $16 \mathrm{~S}$ rRNA and MMP-2 mRNA in tissue specimens from periodontally diseased or healthy sites were assayed by qRT-PCR. The Y-axis represents levels of each RNA in periodontitis specimens relative to healthy specimens. The $\mathrm{X}$-axis represents the source of tissue specimens. Data were analyzed using Student's t-test. (\#) represents $p \leq 0.001$ compared to healthy tissue.

Figure 3. Transcription of multiple chromatin modification enzymes is altered in both periodontally diseased tissue and in T. denticola-challenged PDL cells. Transcription levels of 87 chromatin modification enzymes were examined by qRT-PCR using RNA extracted from healthy and diseased periodontal tissues (Panels A and B, respectively) and from PDL cell lysates collected 9 days after $T d$ challenge as described in Fig. 1 (Panels C and D, respectively).

Panels A and C: Scatter blots showing the transcriptional level of chromatin modification enzymes in periodontally diseased tissues relative to healthy tissue controls (Panel A) and in $T d$-challenged PDL cells relative to unchallenged control cells (Panel C). The Y-axis represents expression level of different enzymes relative to healthy tissue (Panel A) or 
unchallenged control cells (Panel C). The $\mathrm{X}$-axis represents normalized expression of the respective control group.

Panels B and D: Bar-charts showing the significantly downregulated chromatin modification enzymes in periodontally diseased tissues relative to healthy tissue controls (Panel B) and in $T d$-challenged PDL cells relative to unchallenged control cells (Panel D). The Y-axis represents the fold-expression/downregulation level of enzymes relative to unchallenged controls. The $\mathrm{X}$-axis represents different chromatin modification enzymes, with enzyme type grouped by color.

Figure 4. Inhibition of histone phosphorylation using PF-03814735 results in decreased expression and activation of MMP-2, MT1-MMP and TIMP-2, and decreased fibronectin fragmentation in $T$. denticola-challenged and control PDL cells. Cultured PDL cells were pretreated with 0.25 or $0.5 \mu \mathrm{M}$ PF-03814735 (PF) for two days. The cells were then challenged with T. denticola $(T d)$ at $\mathrm{MOI}=100$ or media control for two hours then incubated for three days. The conditioned medium and cell lysates were collected for zymography, western blotting, and qRTPCR. The experiments were repeated three times in triplicate. Data were analyzed using one-way ANOVA. $\left.{ }^{*}\right)$ represents $p \leq 0.05$ compared to the " 0 " concentration in the same group. (\#) represents $\mathrm{p} \leq 0.001$ compared to the " 0 " concentration in the same group.

Panel A: Densitometric analysis of pro-MMP-2 (72kDa) and active MMP-2 (64kDa) detected by gelatin zymography. The $\mathrm{X}$-axis represents different concentrations of histone 
kinase/phosphorylation inhibitor, PF-03814735 (PF) in the control and $T d$ groups. The Y-axis represents fold-gelatinolytic activity of the pro-MMP-2 and active MMP-2 relative to unchallenged and untreated controls.

Panel B: A representative immunoblot of PDL cell culture supernatants probed with a polyclonal anti-fibronectin antibody showing FN fragmentation in conditioned medium from $T d$-challenged PDL cells, control and PF-treated.

Panel C: Bar chart showing transcript levels of MMP-2, MT1-MMP and TIMP-2 in the control and PF-treated PDL cells as determined by qRT-PCR. The Y-axis represents fold-expression level of each gene relative to unchallenged and untreated controls. The X-axis represents different concentrations of PF in the control and $T d$ groups.

Figure 5. Inhibition of DNA methyltransferases using AZAcytidine (AZA) result in decreased expression and activation of MMP-2, MT1-MMP and TIMP-2, and decreased fibronectin fragmentation in T. denticola-challenged and control PDL cells. Cultured PDL cells were pre-treated with 1 or $5 \mu \mathrm{M}$ AZA for four days. The cells were then challenged with $T$. denticola $(T d)$ at MOI $=100$ or media control for two hours then incubated for three days. The conditioned medium and cell lysates were collected for zymography, western blotting, and qRTPCR. The experiments were repeated three times in triplicate.

Panel A: Densitometric analysis of pro-MMP-2 (72kDa) and active MMP-2 (64kDa) detected by gelatin zymography. The $\mathrm{X}$-axis represents different concentrations of DNA 
methyltransferases inhibitor Azacytidine (AZA) in the control and $T d$ groups. The Y-axis represents fold-gelatinolytic activity of the pro-MMP-2 and active MMP-2 relative to unchallenged and untreated controls. Data were analyzed using one-way ANOVA. (*) represents $p \leq 0.05$ compared to the " 0 " concentration in the same group. (\#) represents $\mathrm{p} \leq$ 0.001 compared to the " 0 " concentration in the same group.

Panel B: A representative immunoblot of PDL cell culture supernatants probed a polyclonal anti-fibronectin antibody showing FN fragmentation in conditioned medium from $T d$ challenged PDL cells, control and AZA-treated.

Panel C: Bar chart showing transcript levels of MMP-2, MT1-MMP and TIMP-2 in the control and AZA-treated PDL cells as determined by qRT-PCR. The Y-axis represents fold-expression level of each gene relative to unchallenged and untreated controls. The X-axis represents different concentrations of AZA in the control and $T d$ groups.

Figure 6. Inhibition of DNA methyltransferases using epigallocatechin gallate (EGCG) mediate a decrease in MMP-2 activation, an increase in TIMP-2 transcription and minimal decrease in fibronectin fragmentation in $\boldsymbol{T} d$-challenged PDL cells. Cultured PDL cells were pre-treated with 5 or $10 \mu \mathrm{M}$ EGCG for two days before being challenged with $T$. denticola $(T d)$ at $\mathrm{MOI}=100$ or media control for two hours, then incubated for three days. The conditioned medium and cell lysates were collected for zymography, western blotting, and qRT-PCR. The experiments were repeated three times in triplicate. Data were analyzed using one-way ANOVA. 
(*) represents $p \leq 0.05$ compared to the " 0 " concentration in the same group. (\#) represents $\mathrm{p} \leq$ 0.001 compared to the " 0 " concentration in the same group.

Panel A: Densitometric analysis of pro-MMP-2 (72kDa) and active MMP-2 (64kDa) detected by gelatin zymography. The left 3 lanes represent the control group (unchallenged PDL cells) and the right 3 lanes represent the Td group ( $T d$-challenged PDL cells). The cells in both groups were treated with indicated concentrations of EGCG. The X-axis represents different concentrations of EGCG in the control and $T d$ groups. The Y-axis represents foldgelatinolytic activity of pro-MMP-2 and active MMP-2 relative to unchallenged and untreated controls.

Panel B: A representative immunoblot of PDL cell culture supernatants probed with a polyclonal anti-fibronectin antibody showing $\mathrm{FN}$ fragmentation in conditioned medium from $T d$-challenged PDL cells, control and EGCG-treated.

Panel C: Bar chart showing transcript levels of MMP-2, MT1-MMP and TIMP-2 in the control and ECGC-treated PDL cells as determined by qRT-PCR. The Y-axis represents fold-expression level of each gene relative to unchallenged and untreated controls. The Xaxis represents different concentrations of ECGC in the control and $T d$ groups.

\section{Figure 7. Inhibition of different chromatin modification enzymes mediate alterations in} levels of expression and activation of MMP-2 in Td-challenged and control PDL cell cultures. PDL cells were pre-treated with enzyme inhibitors at the indicated concentrations as follows: curcumin (histone acetyltransferase inhibitor) for two hours (A), $0.5 \mu \mathrm{M}$ and $1 \mu \mathrm{M}$ BIX- 
01294 (histone methyltransferase inhibitor) for two days (B), and $2 \mu \mathrm{M}$ and $5 \mu \mathrm{M}$ tranylcypromine/TCP (histone demethylase inhibitor) for four days (C). The cells were then challenged with $T$. denticola $(T d)$ at $\mathrm{MOI}=100$ or media control for two hours, then incubated for three days. The conditioned medium and cell lysates were collected for zymography. Shown are densitometric analyses of pro-MMP-2 (72kDa) and active MMP-2 (64kDa) detected by gelatin zymography. The $\mathrm{X}$-axis represents different concentrations of enzyme inhibitors in the control and $T d$ groups. The Y-axis represents fold-gelatinolytic activity of the pro-MMP-2 and active MMP-2 relative to unchallenged and untreated controls. Panels: A, curcurmin (Cr); B, BIX-01294 (BIX); C, tranylcypromine (TCP). The experiments were repeated three times in triplicate. Data were analyzed using one-way ANOVA. $\left.{ }^{*}\right)$ represents $p \leq 0.05$ compared to the " 0 " concentration in the same group. (\#) represents $\mathrm{p} \leq 0.001$ compared to the " 0 " concentration in the same group.

Figure 8. Inhibitors of histone phosphorylases and deacetylases reverse $T$. denticolamediated increases in MMP-2 activity and expression in PDL cells. Cultured PDL cells were challenged with $T$. denticola $(T d)$ at $\mathrm{MOI}=100$ or media control for two hours, incubated for three days in serum- and antibiotic-free MEM- $\alpha$ with daily culture medium refreshment, then treated with the following enzyme inhibitors: (Panel A) 0.25 or $0.5 \mu \mathrm{M}$ PF-03814735 (PF) for two days; (Panel B) 0.5 or $1 \mu \mathrm{M}$ apicidin for one day; (Panel C) 0.05 or $0.1 \mu \mathrm{M}$ trichostatin A (TsA) for four days. The conditioned medium and cell lysates were collected for zymography, western blotting, and qRT-PCR. The left portion of each panel shows densitometric analysis of 
pro-MMP-2 (72kDa) and active MMP-2 (64kDa) detected by gelatin zymography. The X-axis represents different concentrations of the indicated inhibitor in the control and $T d$-challenged cultures. The Y-axis represents fold-gelatinolytic activity of the pro-MMP-2 and active MMP-2 relative to unchallenged and untreated controls. The right panel shows transcript levels of MMP2, MT1-MMP and TIMP-2 in the control and inhibitor-treated PDL cells as determined by qRTPCR. The Y-axis represents fold-expression level of each gene relative to unchallenged and untreated controls. The X-axis represents different concentrations of PF in the control and $T d$ groups. The experiments were repeated three times in triplicate. Data were analyzed using oneway ANOVA. $(*)$ represents $p \leq 0.05$ compared to the "0" concentration in the same group. (\#) represents $\mathrm{p} \leq 0.001$ compared to the " 0 " concentration in the same group. 
Figure 1
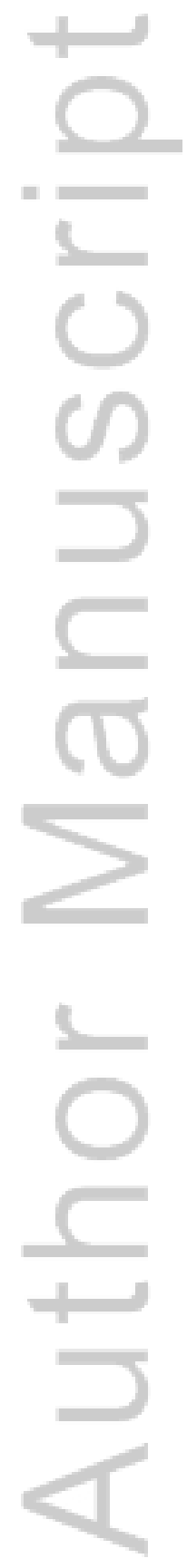

This article is protected by copyright. All rights reserved. 
(A)

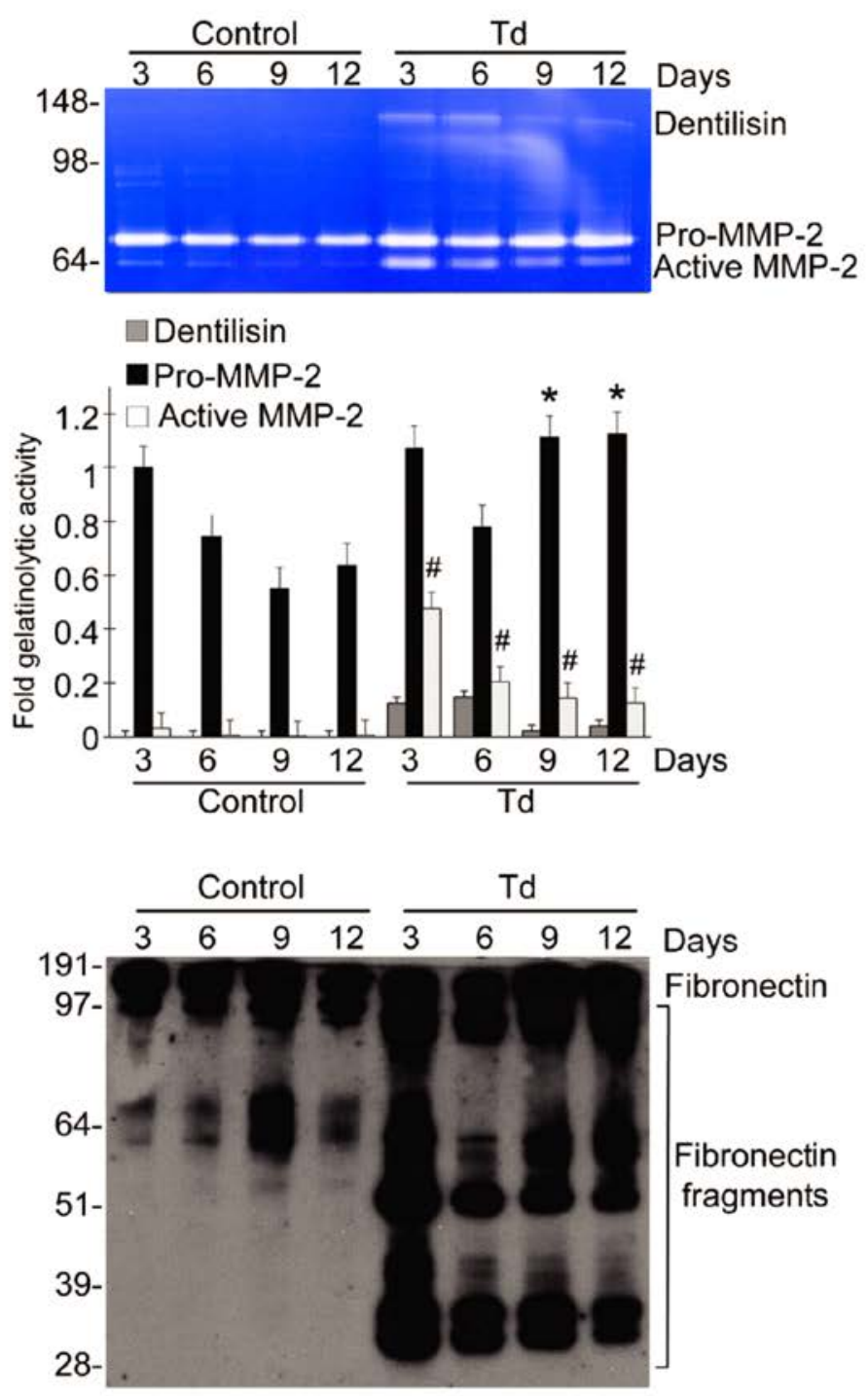

(C)

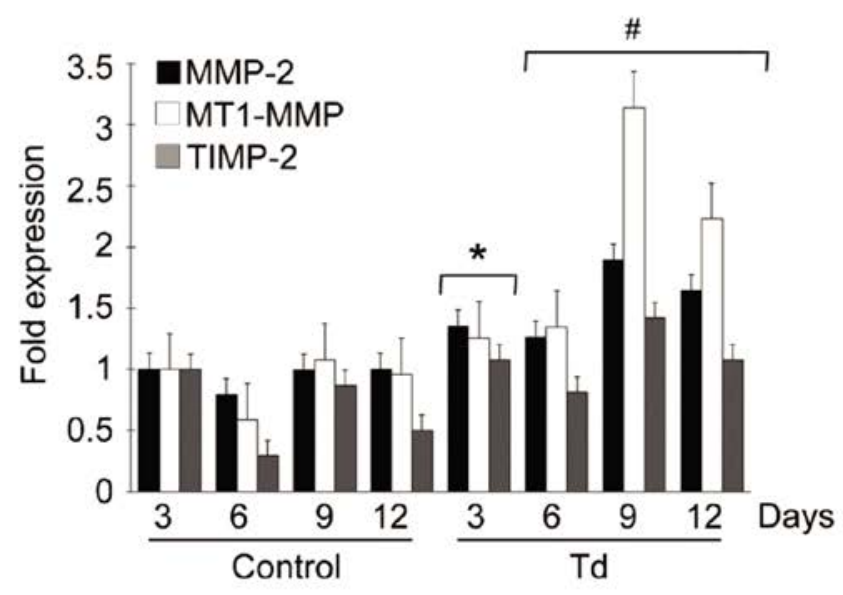


Figure 2

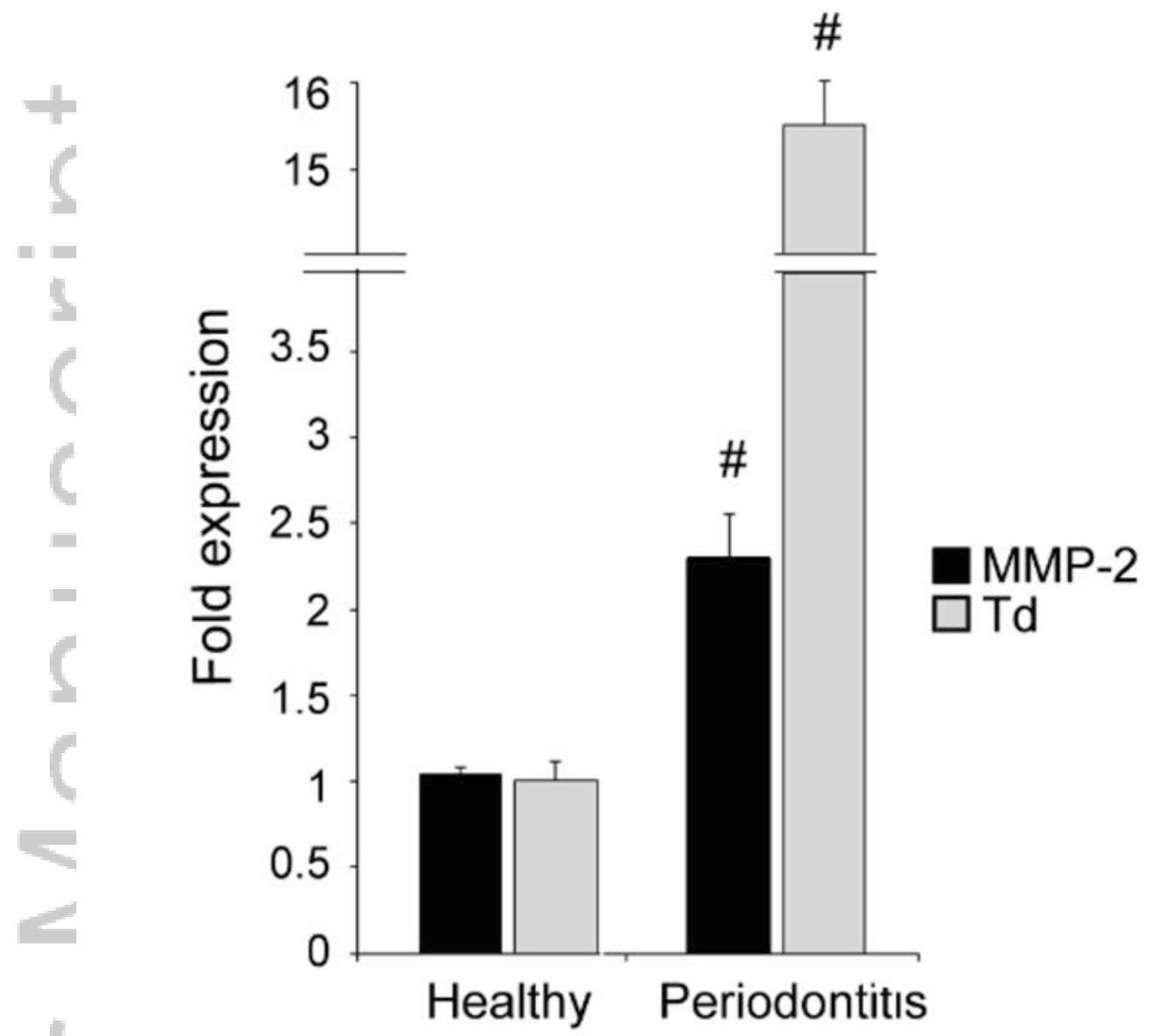

This article is protected by copyright. All rights reserved. 
Figure 3

(A)

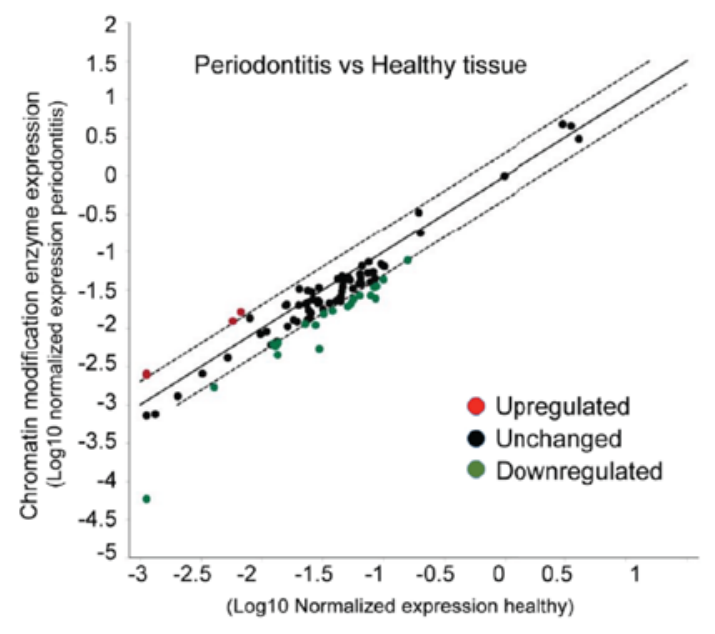

(C)

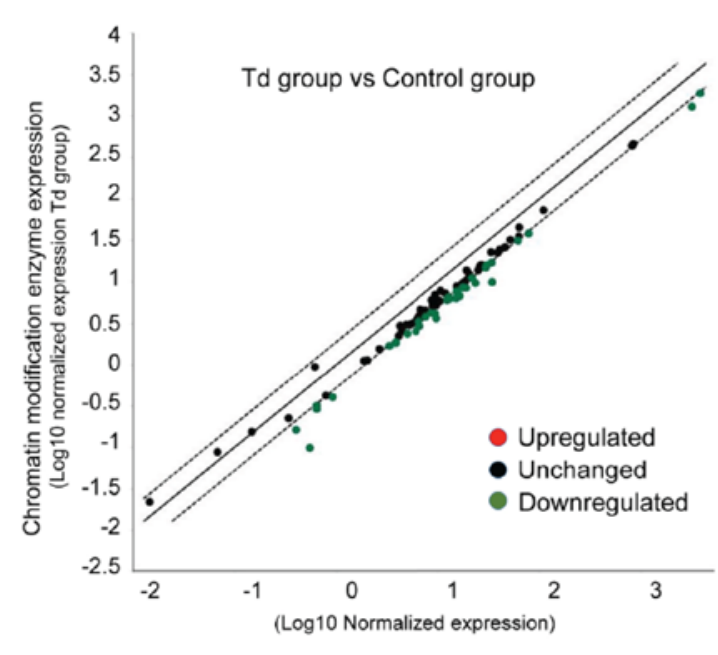

(B)
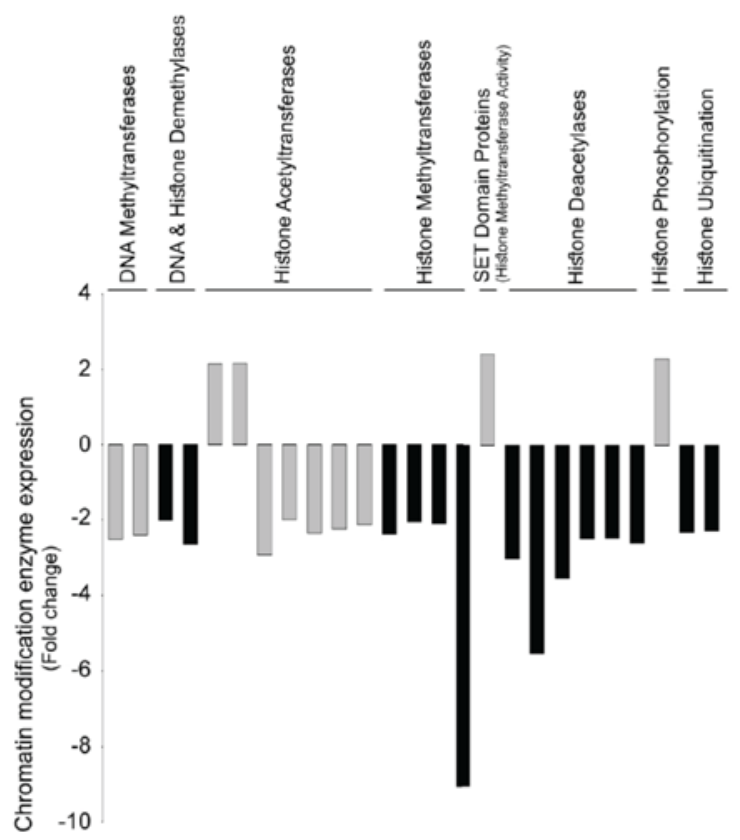

(D)

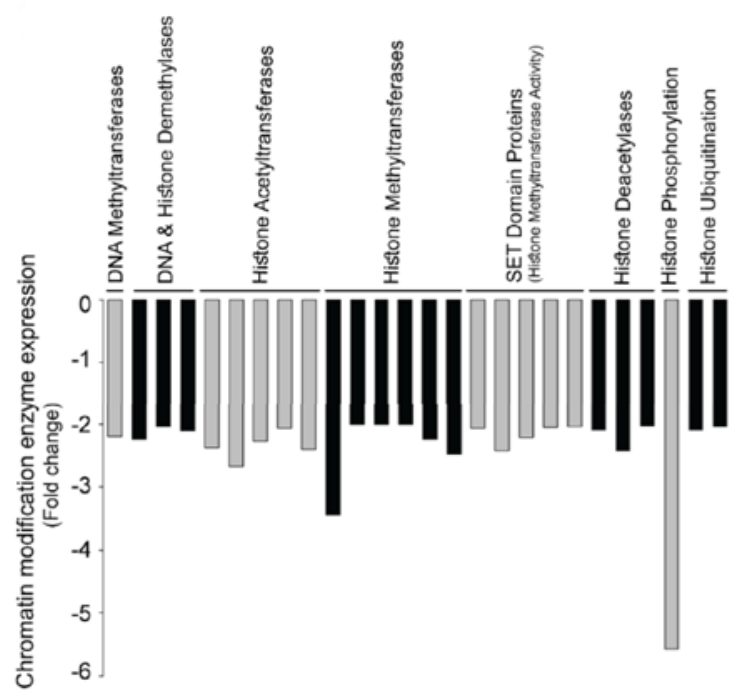




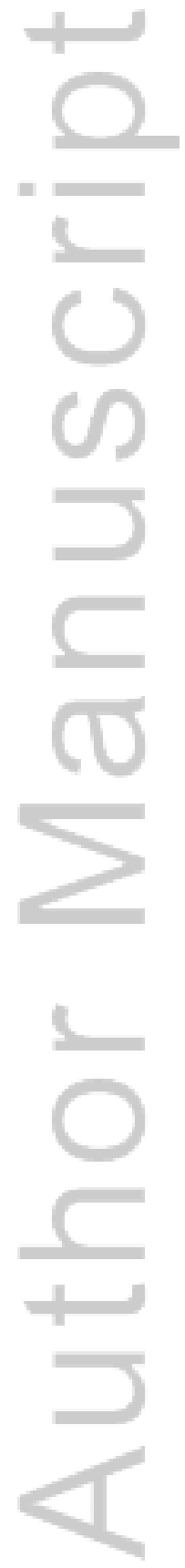

This article is protected by copyright. All rights reserved. 
Figure 4

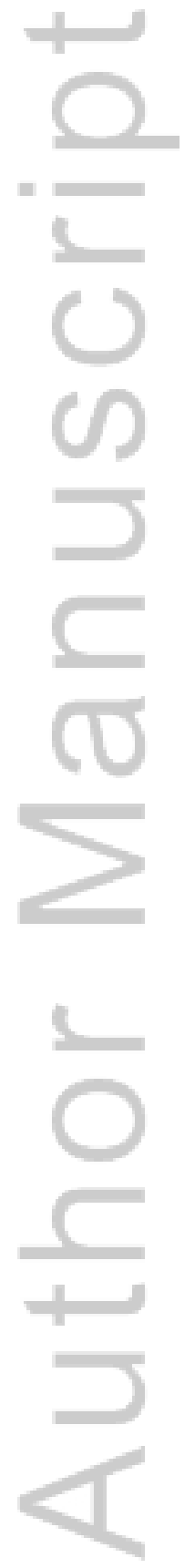

(A)

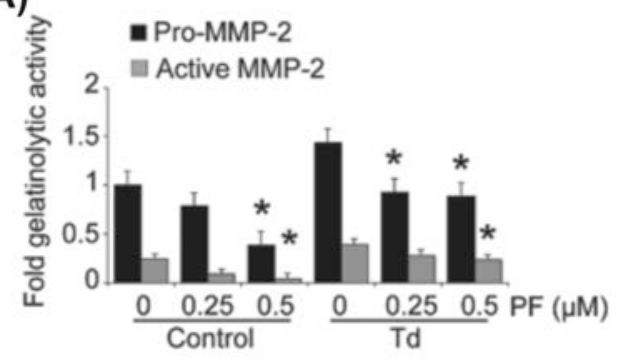

(B)

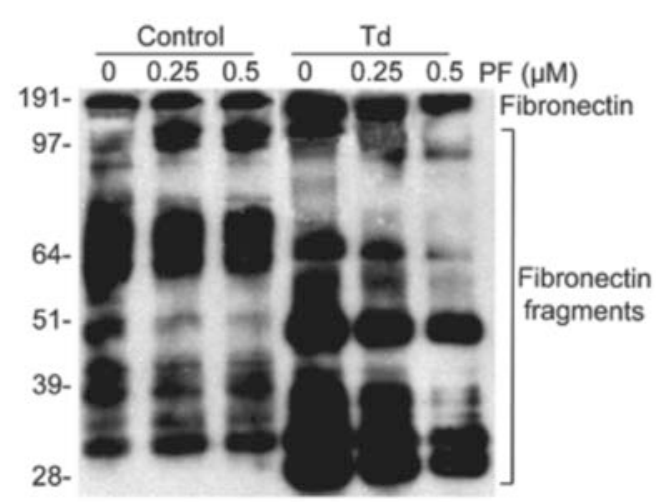

(C)

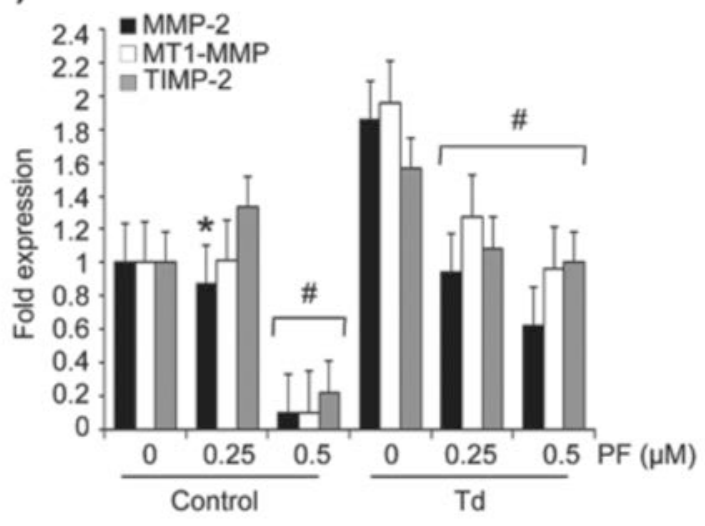


Figure 5

(A)
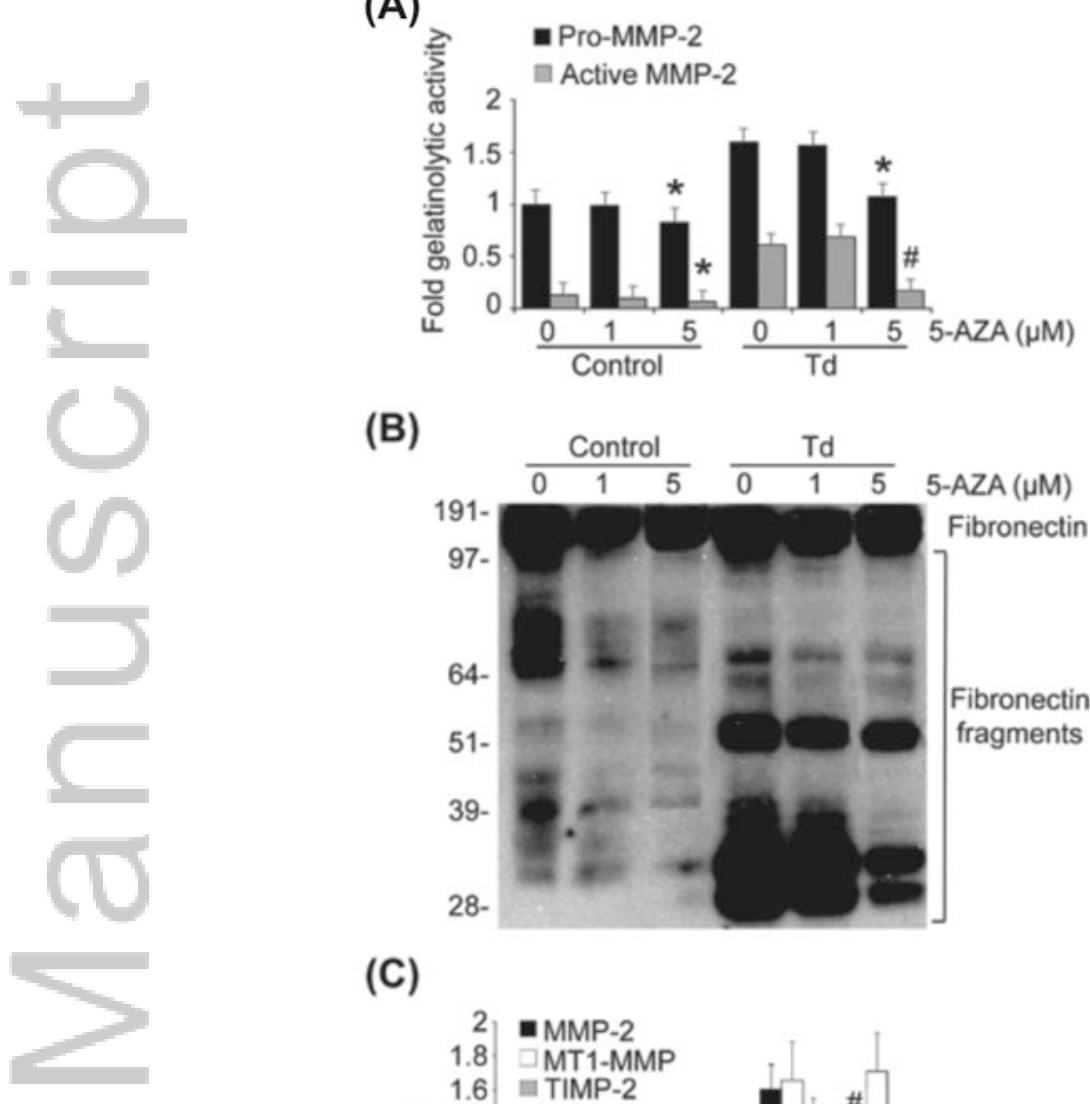

(B)

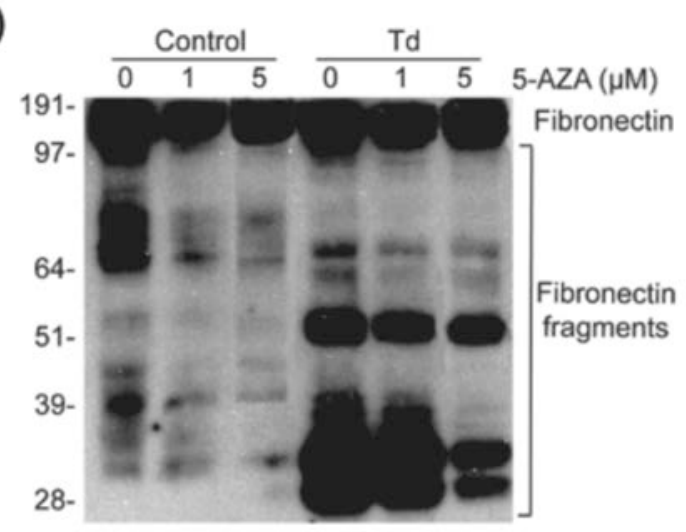

(C)

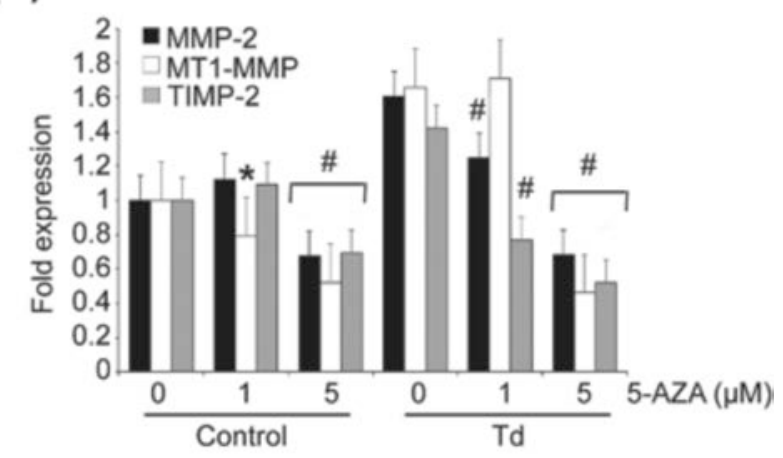

This article is protected by copyright. All rights reserved. 
Figure 6
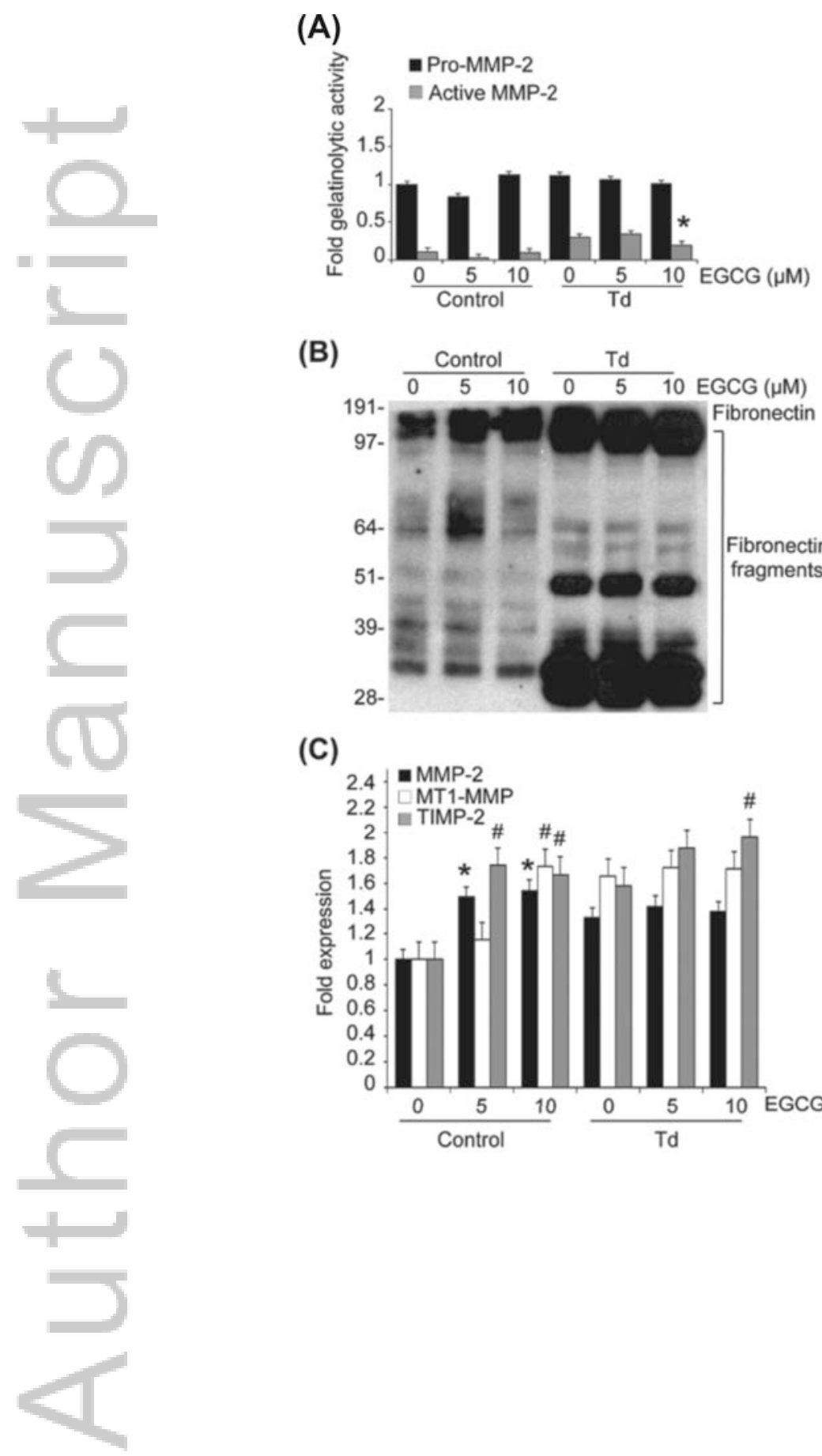

(B)

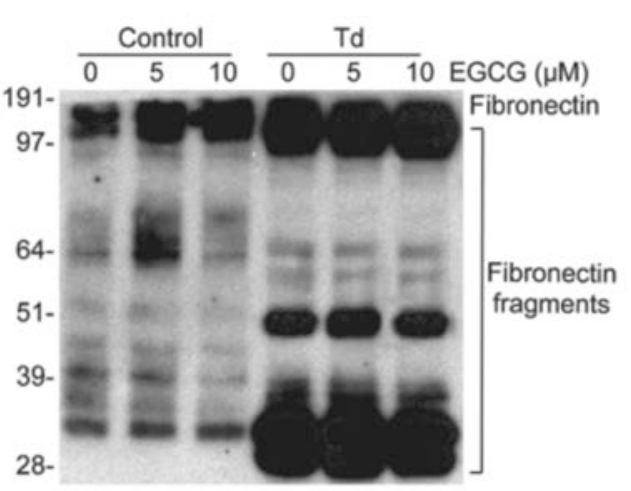

(C)

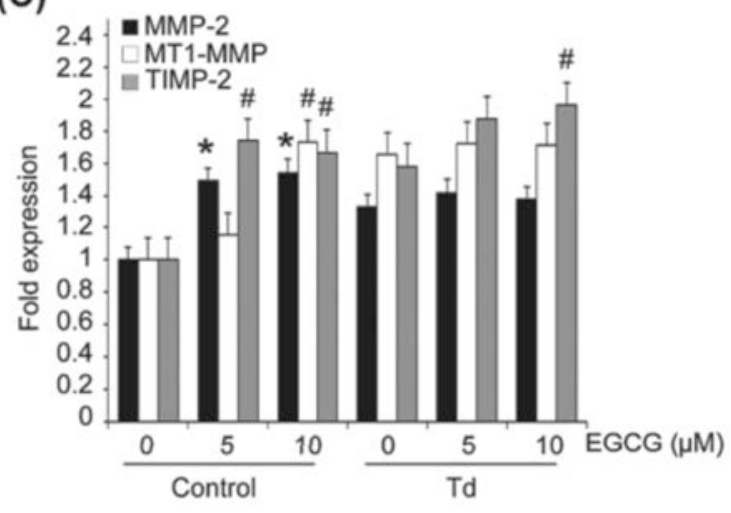

This article is protected by copyright. All rights reserved. 
Figure 7

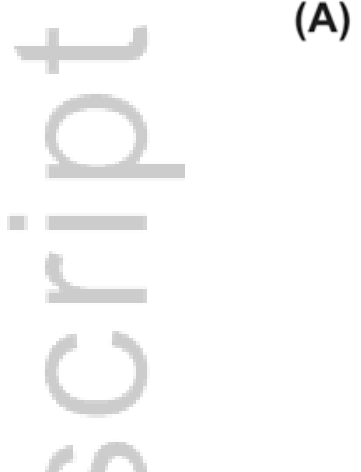

(A)

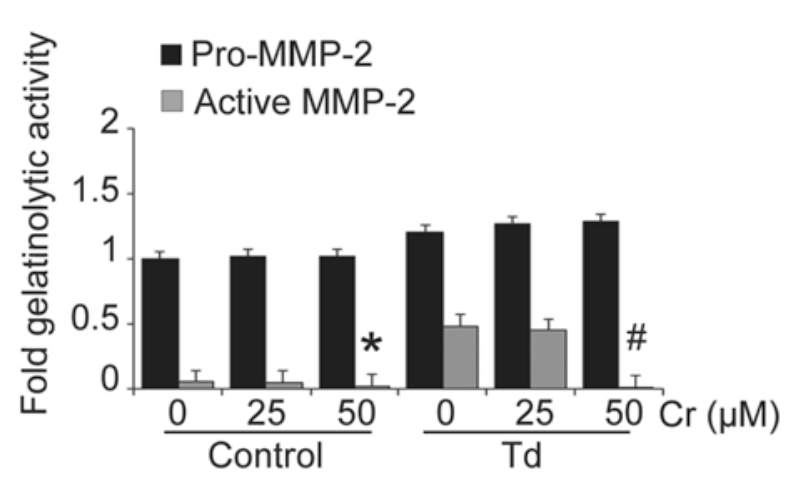

(B)

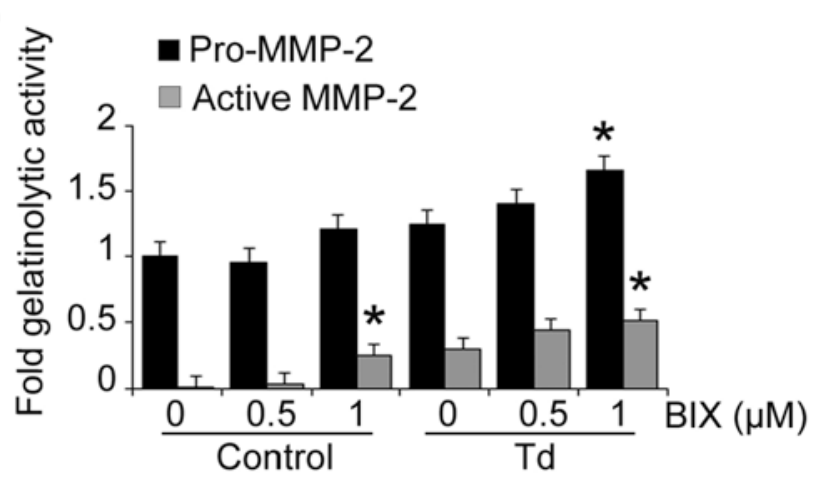

(C)

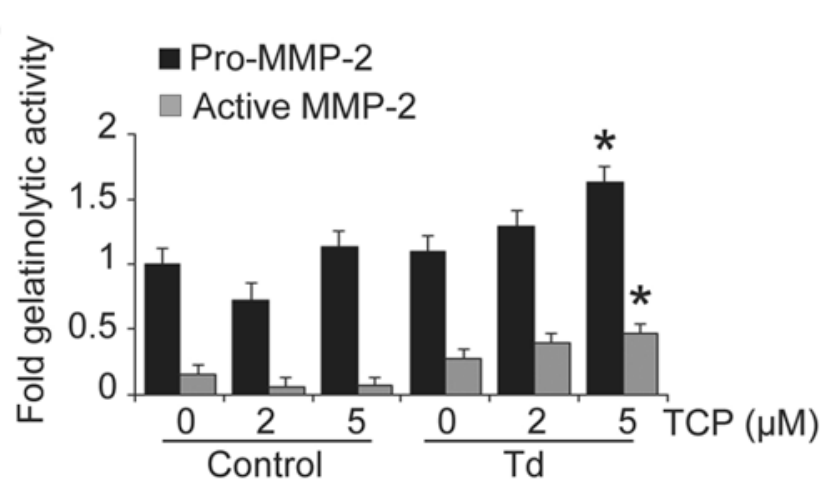

This article is protected by copyright. All rights reserved. 


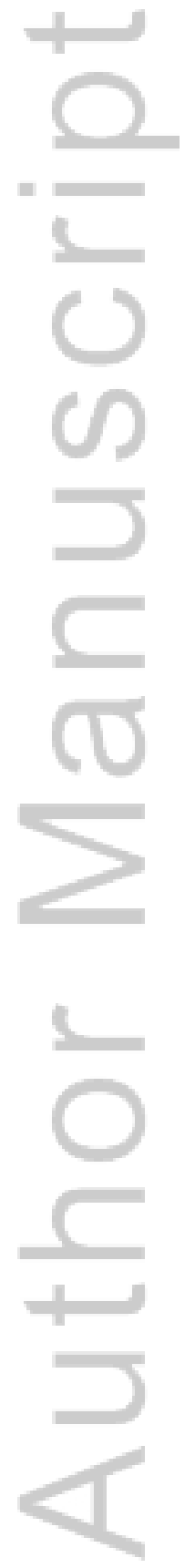

This article is protected by copyright. All rights reserved. 
Figure 8

(A)
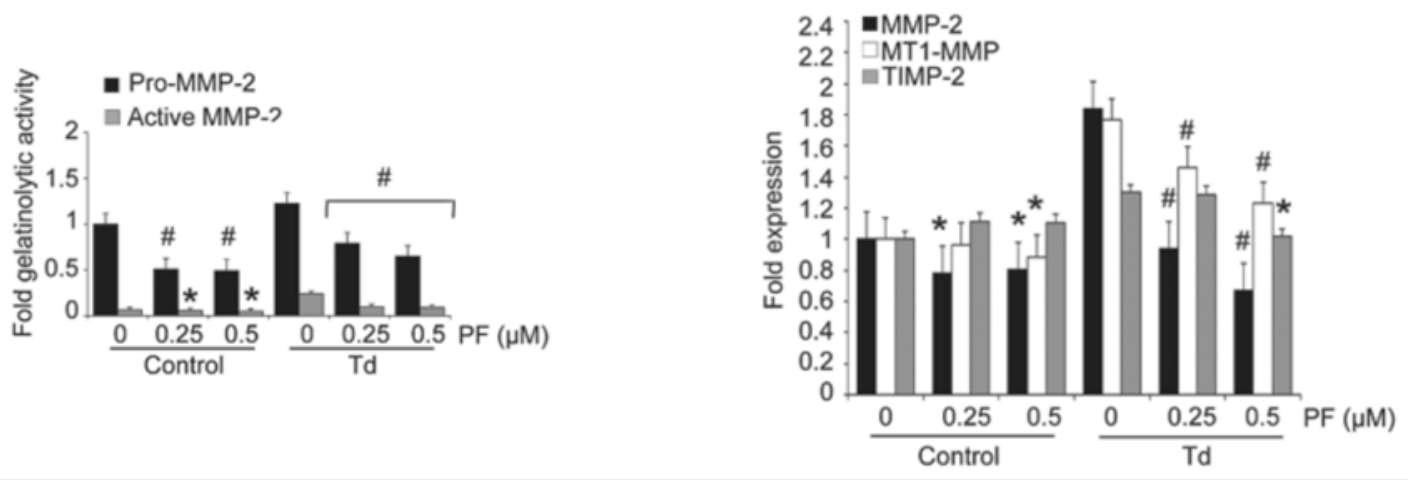

(B)
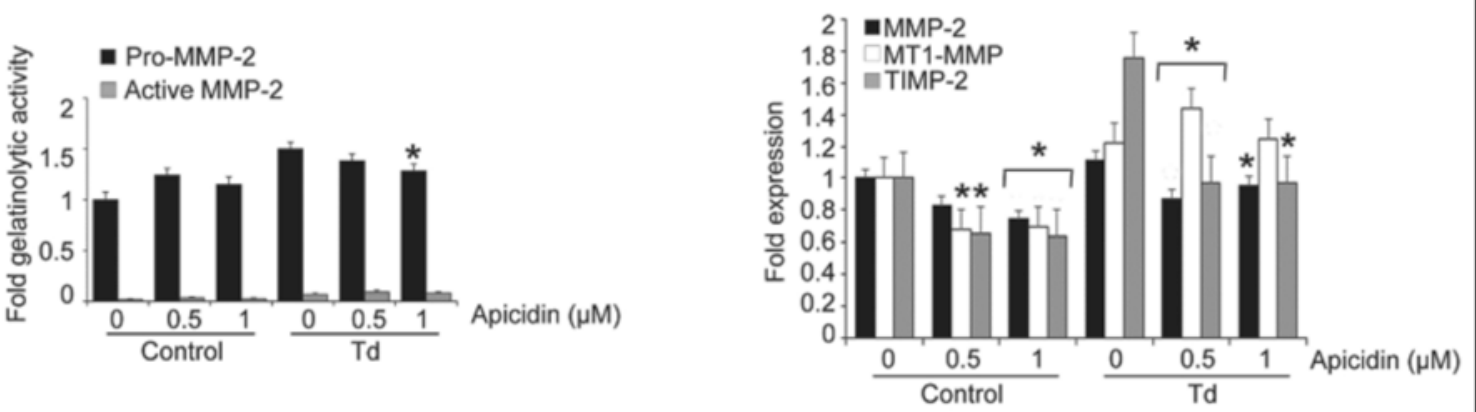

(C)
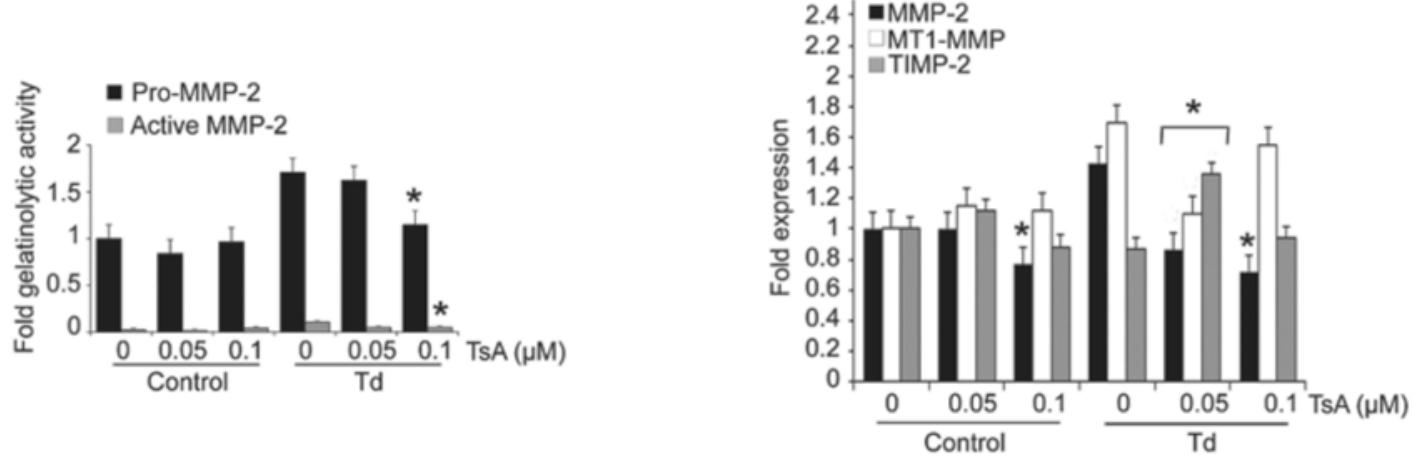

This article is protected by copyright. All rights reserved. 


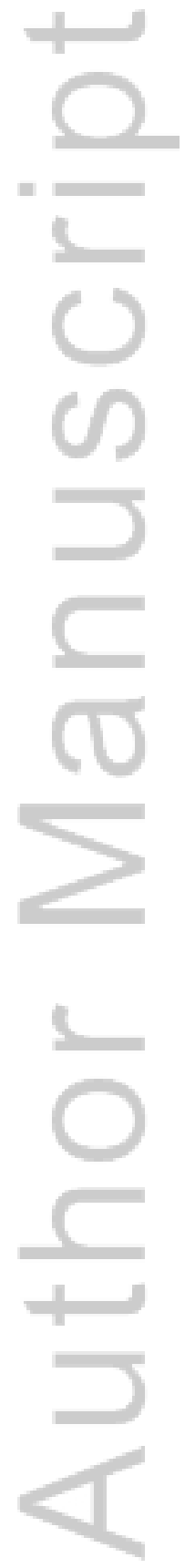

This article is protected by copyright. All rights reserved. 
(A)
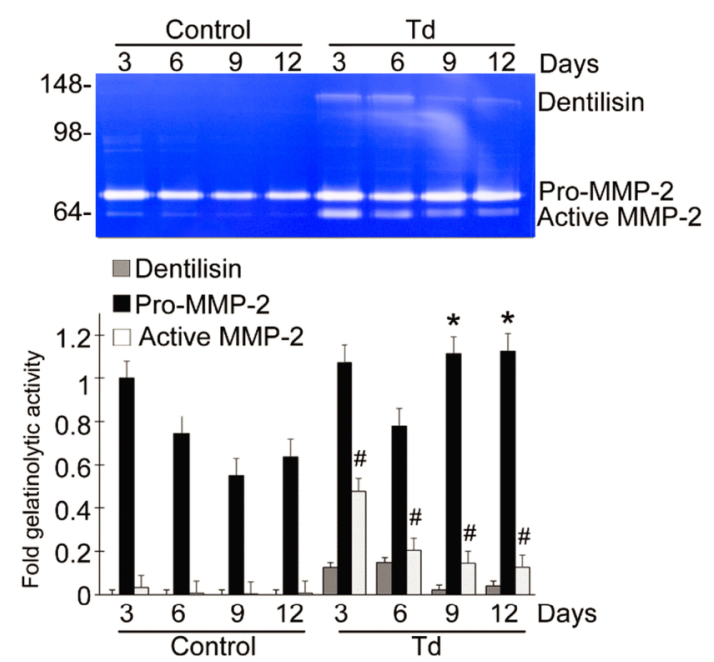

(B)

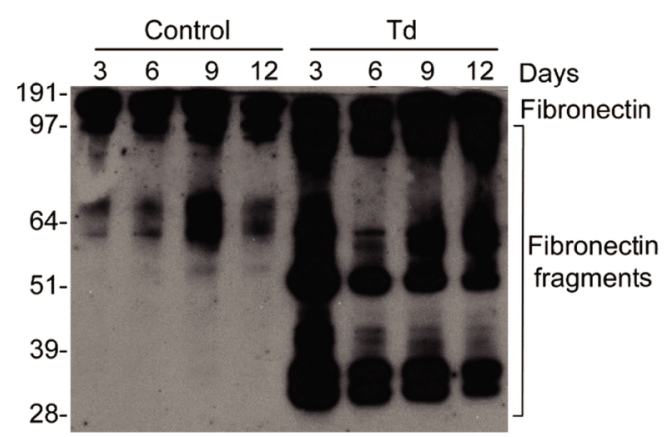

(C)

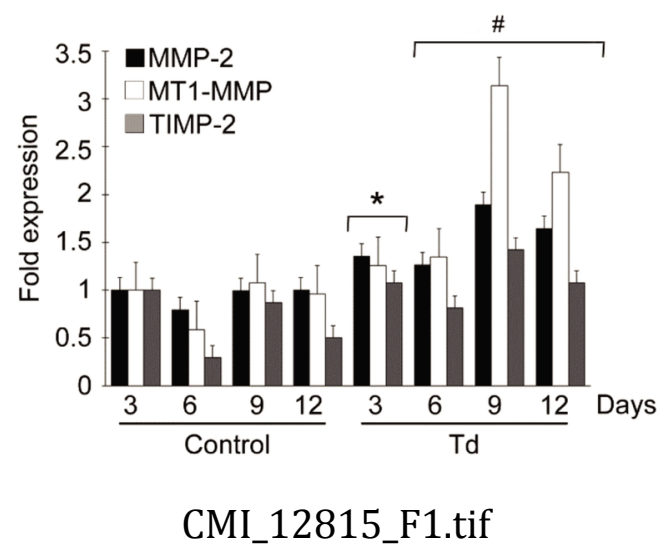

This article is protected by copyright. All rights reserved. 


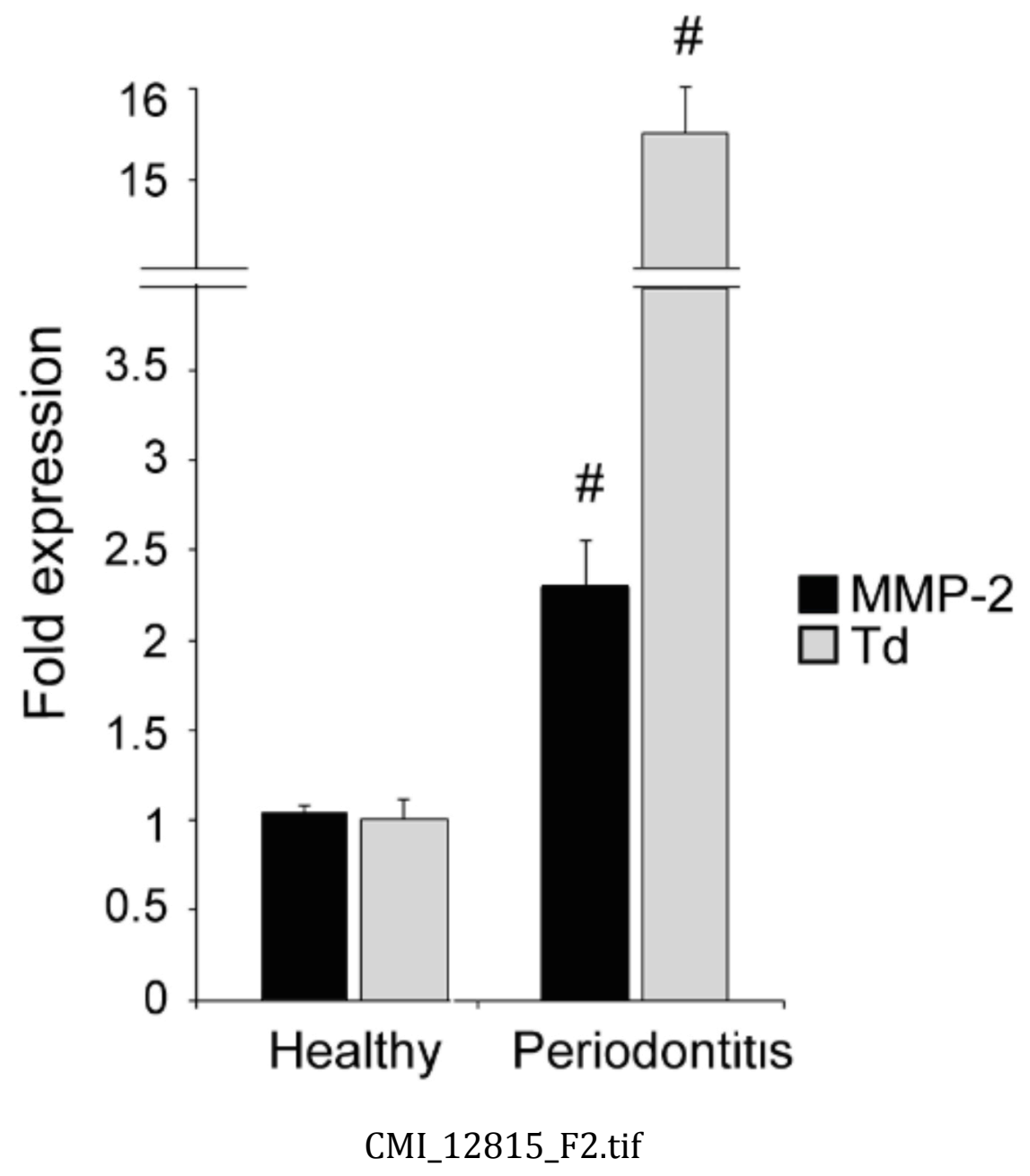

This article is protected by copyright. All rights reserved. 
(A)

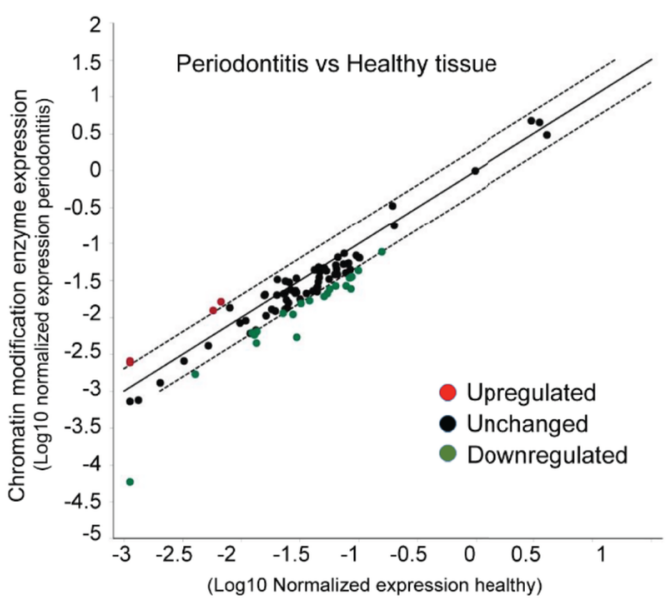

(C)

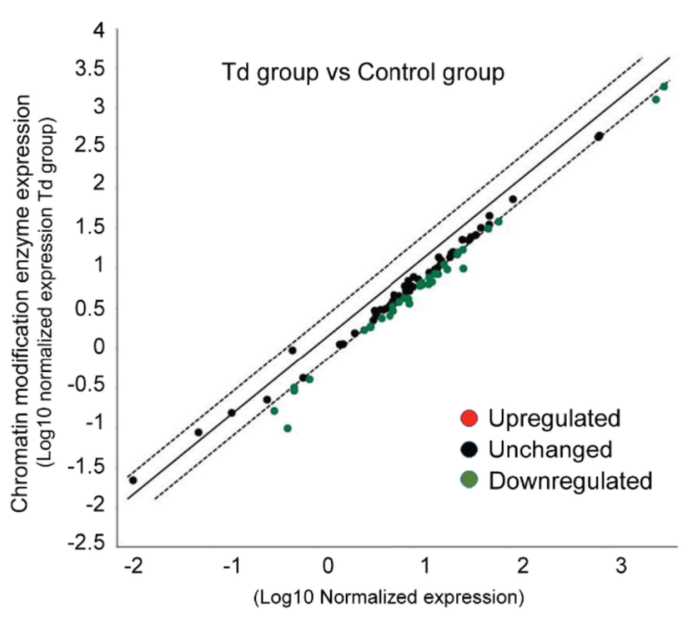

(B)

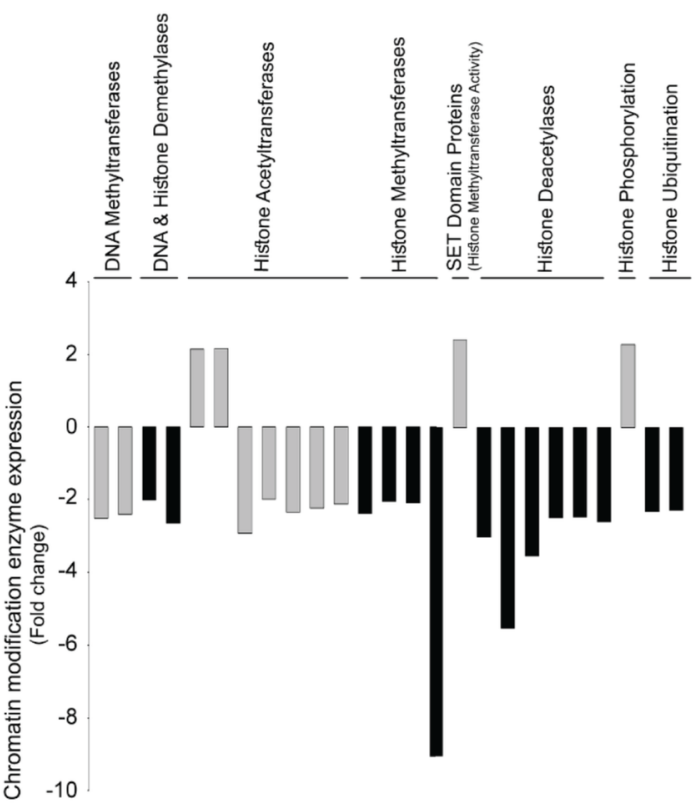

(D)

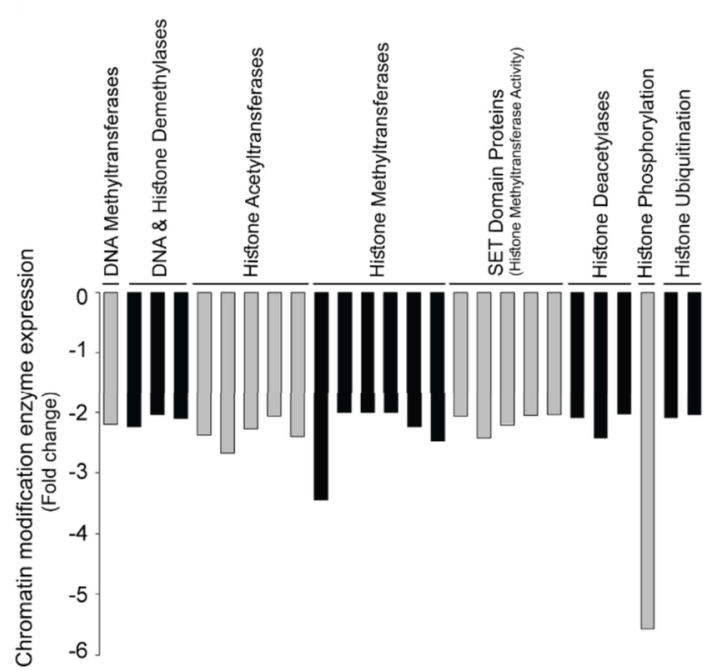

CMI_12815_F3ABCD.tif

This article is protected by copyright. All rights reserved. 


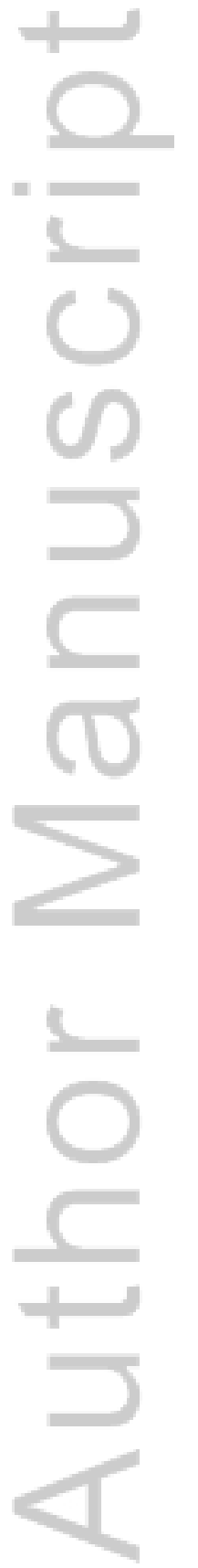

(A)

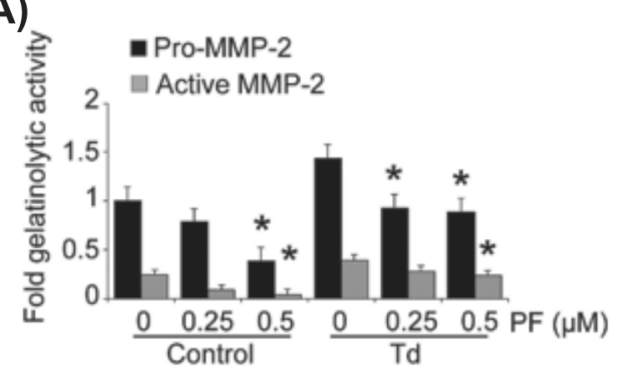

(B)

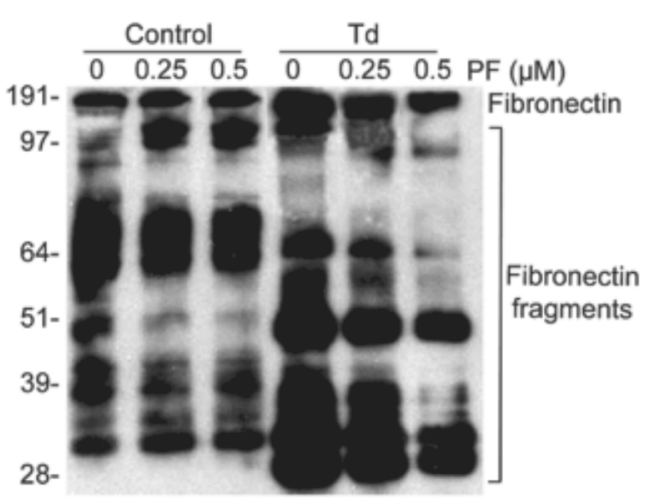

(C)

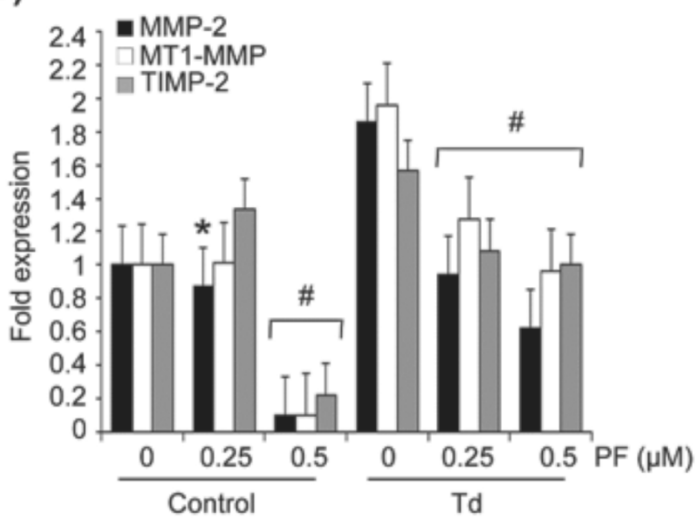

CMI_12815_F4ABC.tif

This article is protected by copyright. All rights reserved. 
(A)

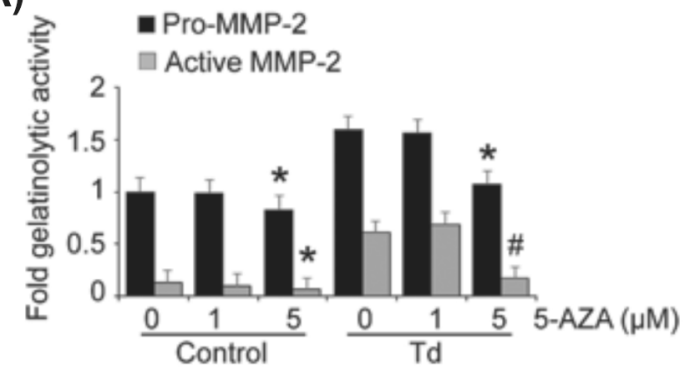

(B)

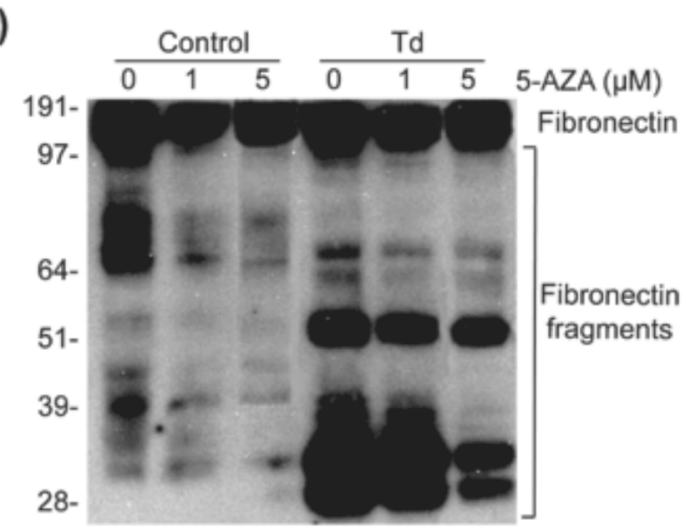

(C)

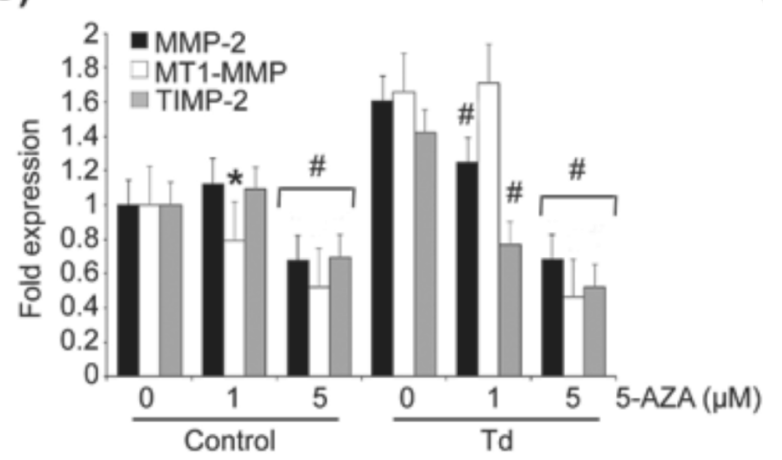

CMI_12815_F5ABC.tif

This article is protected by copyright. All rights reserved. 


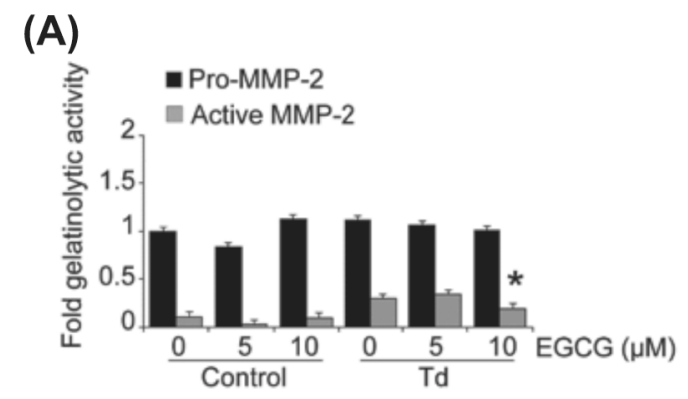

(B)

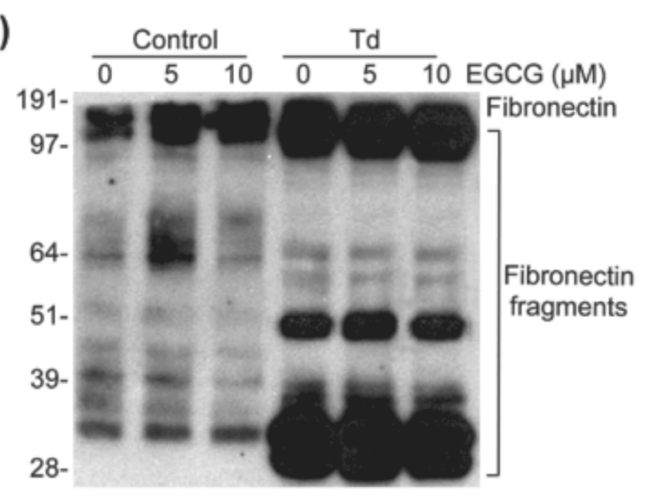

(C)
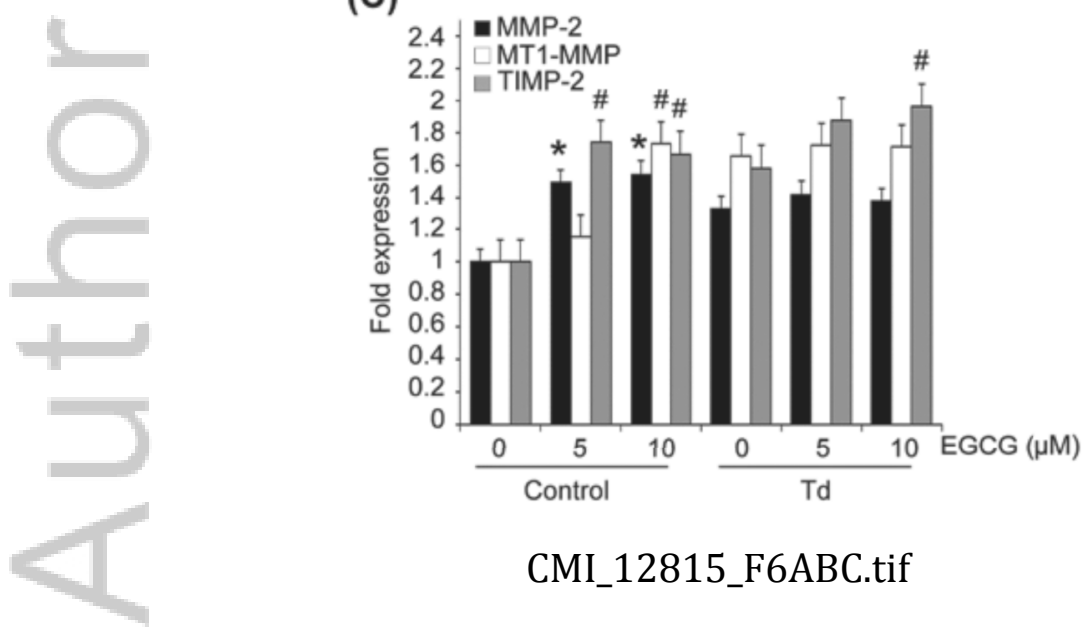

CMI_12815_F6ABC.tif

This article is protected by copyright. All rights reserved. 
(A)

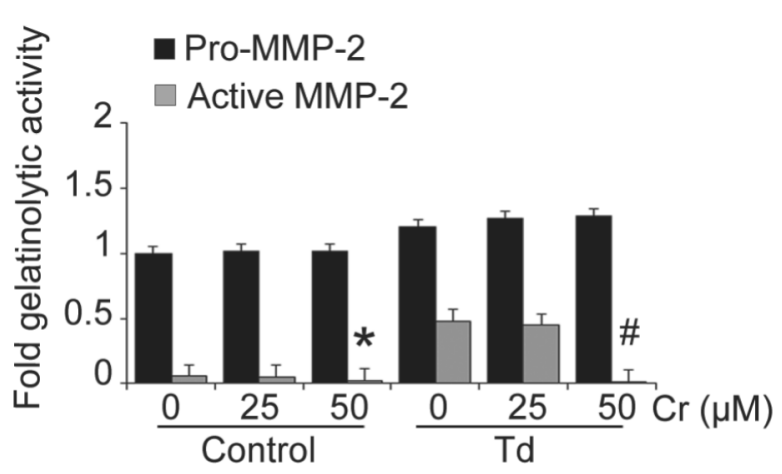

(B)

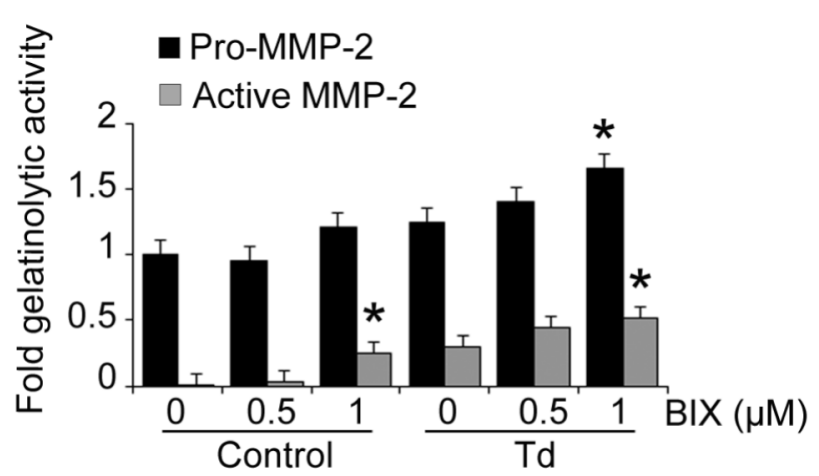

(C)

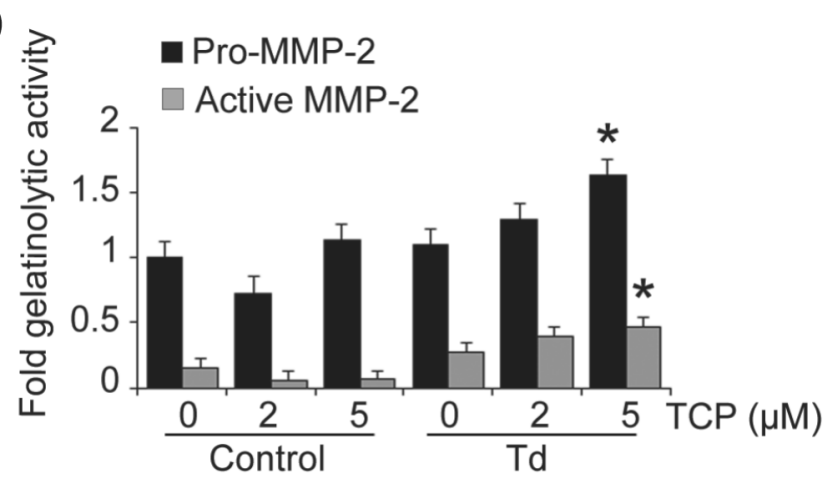

CMI_12815_F7ABC.tif 
(A)

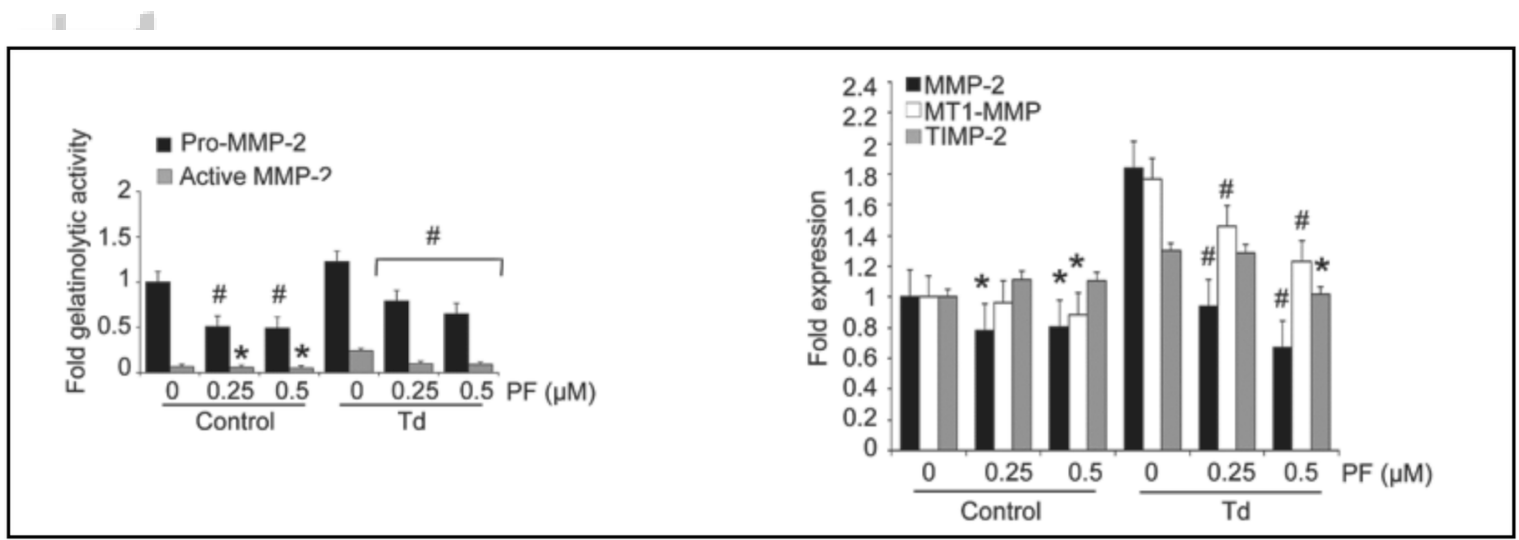

(B)

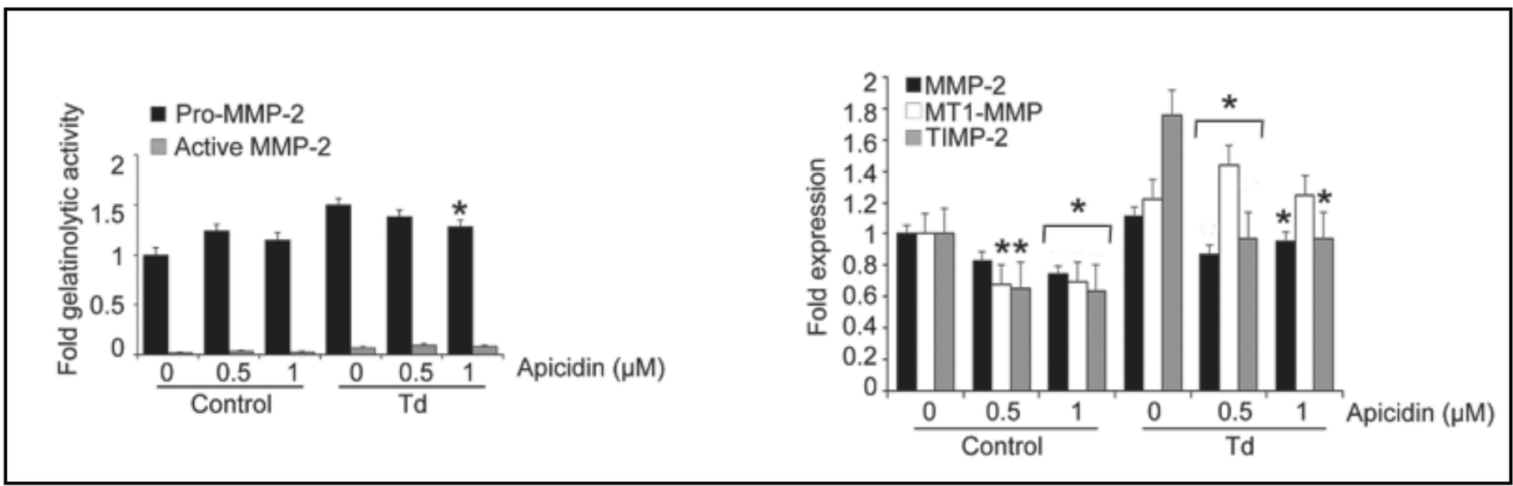

(C)

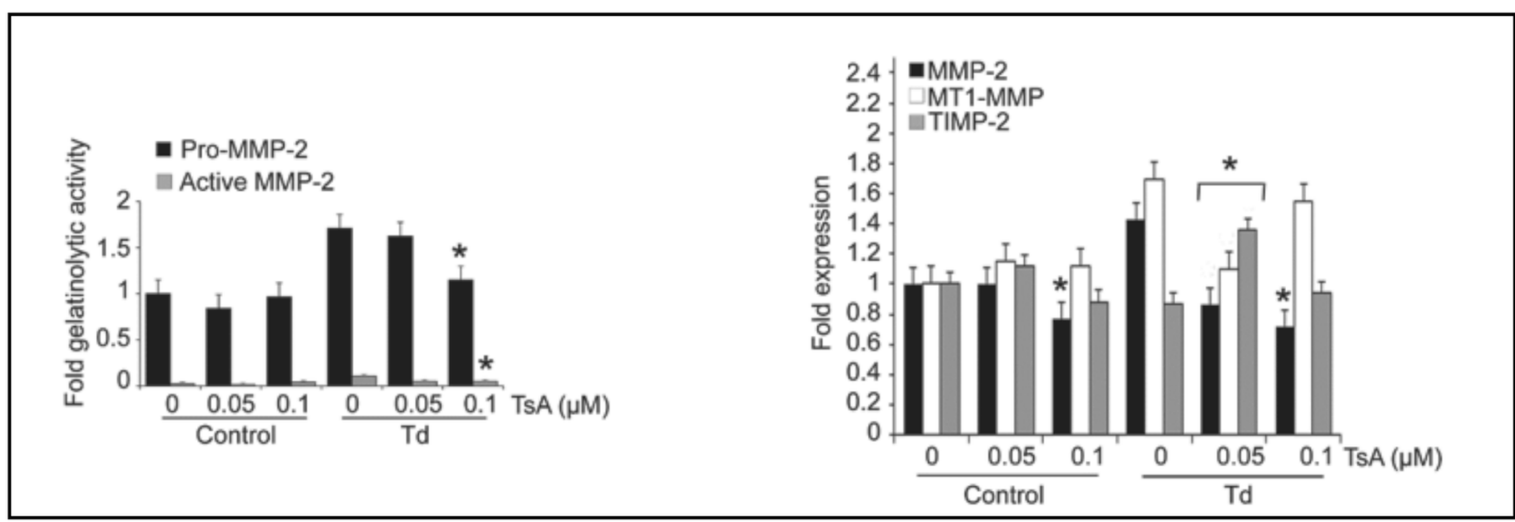

CMI_12815_F8ABC.tif

This article is protected by copyright. All rights reserved. 